Research Article

\title{
Experimental Study of Influence of Support Failures on Rockbursts under True-Triaxial Condition
}

\author{
Guoshao Su, ${ }^{1,2}$ Tianbin Li $\mathbb{D}^{1},{ }^{1}$ Jianqing Jiang $\mathbb{D D}^{2},{ }^{2}$ Guoqing Chen $\mathbb{D}^{1},{ }^{1}$ and Jinghai Mo ${ }^{2}$ \\ ${ }^{1}$ State Key Laboratory of Geohazard Prevention and Geoenvironment Protection, Chengdu 610059, China \\ ${ }^{2}$ Key Laboratory of Disaster Prevention and Structural Safety of Ministry of Education, School of Civil and \\ Architecture Engineering, Guangxi University, Nanning 530004, China \\ Correspondence should be addressed to Jianqing Jiang; jiangqing880201@163.com
}

Received 29 March 2018; Revised 18 July 2018; Accepted 7 August 2018; Published 23 September 2018

Academic Editor: Gaofeng Zhao

Copyright (c) 2018 Guoshao Su et al. This is an open access article distributed under the Creative Commons Attribution License, which permits unrestricted use, distribution, and reproduction in any medium, provided the original work is properly cited.

\begin{abstract}
Supports can effectively reinforce the surrounding rock after excavation in underground engineering. However, a support failure may cause an extremely intense rockburst. Hence, the influences of support failures, including support forces, support failure timings, and support failure rates, on rockbursts were systematically investigated in the present study. Unloading tests on rock specimens, using a true-triaxial rockburst test system, were performed to simulate rockbursts induced by support failure. The experimental results indicate that increasing support forces increased the prepeak accumulated elastic strain energy, the kinetic energy of the ejection fragment, and the ratio between the kinetic energy and release strain energy, whereas the damage to the rock specimens declined. During the testing process, the longer it took to unload the minimum stresses was, which means that the later the support failed, the greater the prepeak accumulated elastic strain energy was, the kinetic energies of the ejection fragments were, and the ratio of the kinetic energy and release strain energy was. Furthermore, as the support failure rate incremented, the kinetic energies of the ejection fragments of the rockbursts linearly increased, the failure mode of the rock changed from static failure to dynamic rockbursts, and the intensities of the rockbursts increased.
\end{abstract}

\section{Introduction}

Rockburst is a typical geological disaster during underground excavation in high-stress grounds and frequently accompanied with abrupt rock fragment ejection [1-5]. For their incredible nature, rockbursts often induce casualties, equipment damage, and economic losses [6]. To avoid rockburst, engineers always use support to strengthen the rocks surrounding the underground spaces [7]. However, the rockbursts, even intensive ones (Figure 1), still occur in supported tunnels after excavation [6, 8-10]. In addition, from the investigation of rockbursts occurring during construction of Jinping II Hydropower Station, it is noted that most rockburst was encountered in rock masses where the rigid or flexible supports were applied [4], and subsequently, these supports usually failed. The change in the stress state of the supported rock masses during the rockburst process can be described as follows. As shown in
Figure 2(a), supports can raise the carrying capacity of the surrounding rock by increasing the radial stress [7]. Upon supports' fail, the radial stresses of rock mass on the excavated boundary vanish, and the radial stress of rock mass near the excavated boundary decreases to a low level. Leading to a decrease in carrying capacity of sound rocks, as shown in Figure 2(b). In this situation, dynamic rock failure will be induced, triggering the release of elastic strain energy. Therefore, Rockburst occur. Consequently, the rockburst closely relates with the support failure.

Over the past few years, considerable efforts have been devoted to investigating the supports for tunnels. Kaiser [11] summarized three primary functions of conventional supports: (1) reinforce the rock mass, (2) retain broken rock mass, and (3) securely hold or tie back the retaining rock elements to the stable ground. In addition to have above method functions, support under rockburst conditions needs to resist the dynamic loads and large rock dilation due 


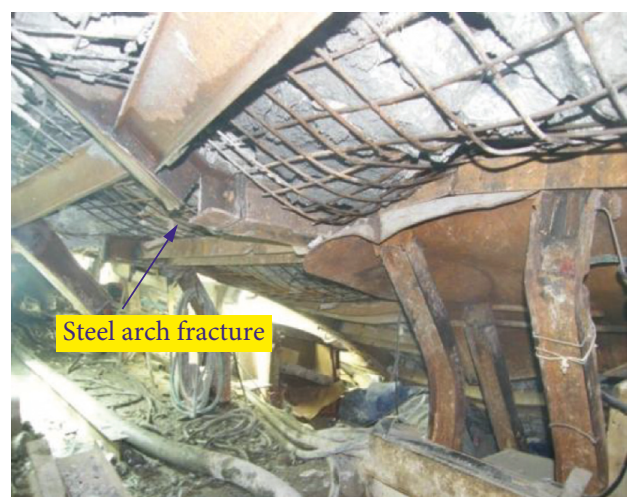

(a)

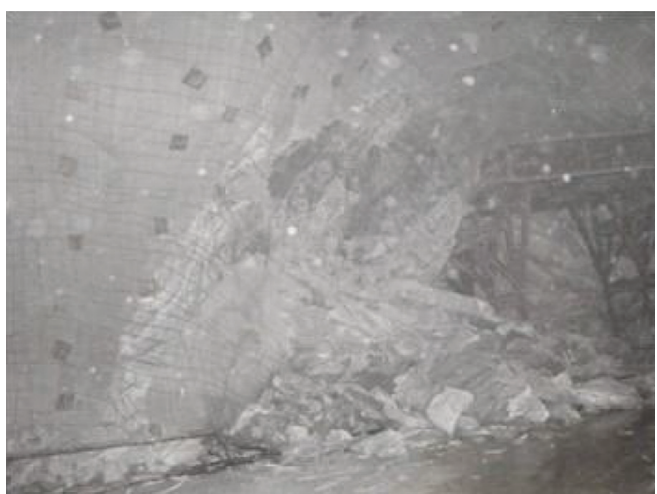

(b)

FIGURE 1: Support failure triggers rockburst at the Jinping II Hydropower Station in (a) diversion tunnel \#2 and (b) diversion tunnel \#4 [6].

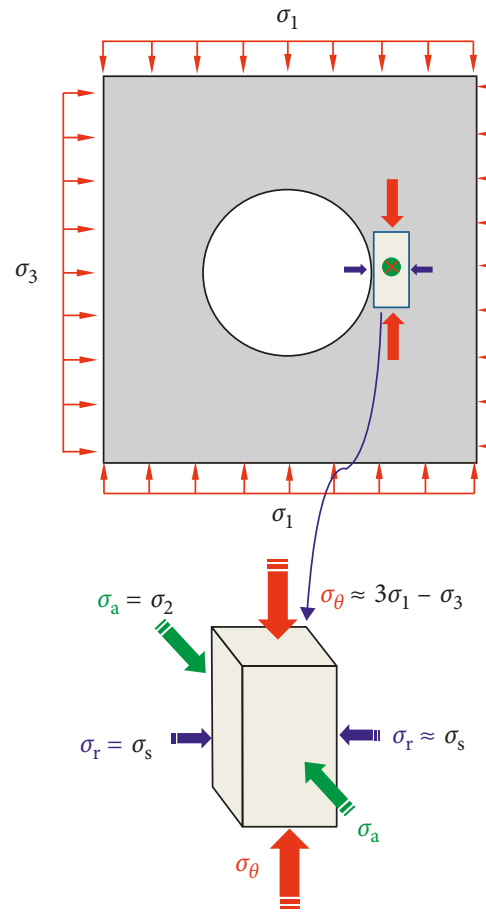

(a)

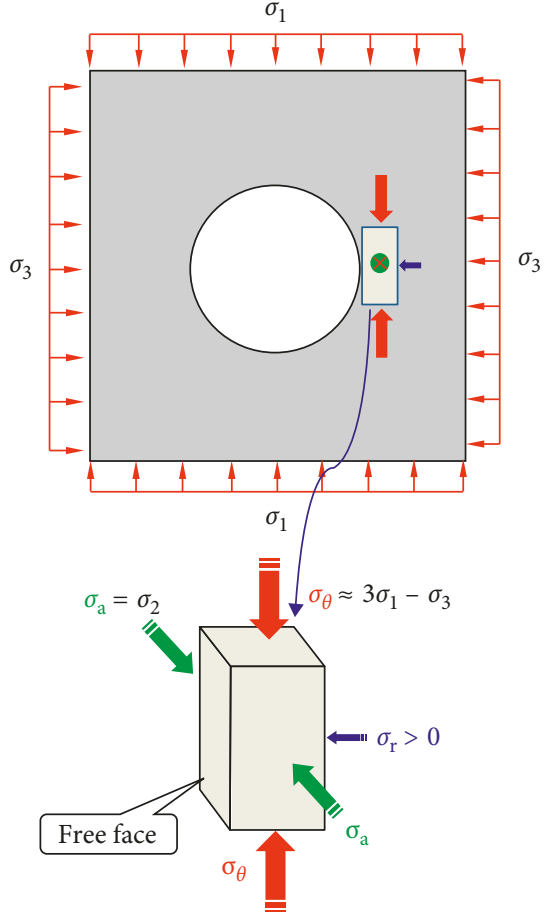

(b)

FiguRE 2: The stress state of the supported rock masses during rockburst: (a) before support failure and (b) after support failure. $\sigma_{1}, \sigma_{2}$, and $\sigma_{3}$ are the major, intermediate, and minor initial stresses, respectively. $\sigma_{\theta}, \sigma_{\mathrm{a}}$, and $\sigma_{\mathrm{r}}$ denote the tangential, axis, and radial stresses of rock masses near the excavated boundary. $\sigma_{\mathrm{s}}$ is the stress provided by the support.

to dynamic rock failure. For this reason, specific design principles for support were presented [3], specific supports such as constant damping large deformation bolt were produced [12], and specific design tools such as BurstSupport were developed [13]. However, existing researches focus on support methods and construction for controlling rockbursts. The characteristics of rockbursts under the support failure, corresponding to the rapid decrease of radial stress, have not been systematically studied.

As a useful way to study the rock failure, experimental tests such as uniaxial tests [14-16] and conventional triaxial tests [17-19] are carried out to investigate rockbursts.
However, these uniaxial and conventional triaxial tests fail to describe stress changes in the surrounding rock near the free boundaries during excavation. In addition, rock fragment ejection, which is a peculiar feature of rockbursts comparing to static brittle rock failure, is solemnly involved. To address these issues, improved true-triaxial tests were proposed. $\mathrm{He}$ et al. [20] conducted a fast unloading test under true-triaxial conditions and successfully simulated the rockburst ejection process in a deep underground excavation. Furthermore, by performing one free face true-triaxial test, Zhao et al. [21, 22] studied on the influences of the unloading rate and aspect ratio on rockbursts, Gong et al. [23] investigated the 
influence of preexisting fractures on the angle of new fractures in the rockburst process, and $\mathrm{Su}$ et al. $[24,25]$ studied the influence of tunnel axis stress and initial damage of rock masses on the characteristics of strainbursts. However, most existing tests have focused on rockbursts under the unsupported condition. However, the experimental investigation on rockbursts under the supported failure condition has not been implemented.

The aim of this work was to investigate the influence of support failure on rockbursts. First, an unloading test on granite was performed using a true-triaxial rockburst system to simulate a rockburst triggered by a support failure. The influence of the support force, support failure timing, and the support failure rate on the rockburst were then studied in terms of the kinetic energy of the ejected fragments, final failure form, prepeak elastic strain energy, and the size distribution of all the fragments.

\section{Test System and Methodology}

2.1. Test System. The rockburst test machine (Figure 3), which was developed by Guangxi University of China, was used in the present study. It can load/unload independently in three mutually principal stress directions, with a maximum capacity of $5000 \mathrm{kN}$ in the vertical direction and $3000 \mathrm{kN}$ in the horizontal directions. Furthermore, during a test, the stress on one surface of the prismatic specimen could be unloaded abruptly while the stress on the opposite side of the unloading surface was kept constant, which can simulate the process of rapid stress variation in underground excavations. The unloading device is shown in Figure 4; when the stress on the surface of the specimen almost vanishes, the loading plate will be drawn away by the stretched high-flexible spring, exposing a free face. It should be noted that in the present study the rock specimen directly contacts with the loading plate. The end fiction between rock specimen and loading plate is used to simulate the constraint of surrounding rock element to the target rock element [25]. In addition, the loading plates fully cover the six surfaces of the rock specimen, i.e., there is no gap between the rock specimen and loading plate.

A high-speed camera system (two high-speed cameras) and the $\mathrm{AE}$ system were used to monitor the rockburst process. The layout of the high-speed camera system is presented in Figure 5.

2.2. Rock Specimen. The intact rectangular prismatic rock specimens, which had the dimensions of $100 \mathrm{~mm} \times 100 \mathrm{~mm} \times$ $200 \mathrm{~mm}$, were granodiorite from the Guangdong province in China. P-wave velocities of all the experimental specimens were approximately $5.2 \mathrm{~km} / \mathrm{s}$ which indicates that all the specimens had similar damage levels. The uniaxial compression strength was approximated as $159 \mathrm{MPa}$, and the density was $2644 \mathrm{~kg} / \mathrm{m}^{3}$.

2.3. Method for Estimating Kinetic Energy. The kinetic energy of ejected fragments is a significant index for evaluating the rockburst intensity. In general, the kinetic energy can be calculated using the following formula:

$$
E_{\mathrm{k}}=\frac{1}{2} m v^{2}
$$

where $m$ is the mass of the ejected fragments and $v$ is the speed of the ejected fragments. The mass $m$ of the ejected fragments can be directly weighed. The speed can be obtained by analyzing the rockburst process video recorded by the high-speed cameras. As shown in Figure 6, the motion trace of an ejection fragment could be tracked first, and then the ejection rate could be calculated by dividing the distance by the time interval. It should be noted that there are angles between the ejection directions of the fragments and the recording direction of the high-speed cameras, as shown in Figure 5, which caused the measured rate to differ from the actual rate. According to the arrangement of the high-speed cameras, the relationship between the measured rate $v^{\prime}$ and actual rate $v$ can be described as $v=v^{\prime} / \cos \theta$, where $\theta$ is the angle between the measured and actual rates. Through this relation, the actual rates could be obtained. For the highspeed camera \#1, the $\theta$ is $75^{\circ}$. For the high-speed camera \#2, $\theta$ is $60^{\circ}$.

To determine the kinetic energy, the particle sizes of the fragments should also be determined. Because the number of fragments collected after the tests was extremely large, it was difficult to find the right ejected fragments that corresponded to the ones in the video. Therefore, we adopted a method for measuring the particle sizes of the fragments in the video. The method can be described as follows. First, the actual and video-measured dimensions of the length of the specimen were measured using the measuring tool and analysis software, respectively. Next, the ratio of the actual dimension to video-measured dimension was calculated. The actual particle size of the specific fragment in the video was determined using the video-measured particle size and the ratio.

The kinetic energy measurement method for the ejection fragments used in this study is described in detail as follows. The rock fragments were first classified into several groups according to the particle sizes. Three particle sizes (beyond $9.5 \mathrm{~mm}$, between 4.75 and $9.50 \mathrm{~mm}$, and less than $4.75 \mathrm{~mm}$ ) were used to divide the rock fragments into groups in our study. In addition, the quality of each group of fragments was measured. For the fragments with the particle sizes beyond $9.5 \mathrm{~mm}$, the ejection rate was the average of four rates of points on the fragment. For the fragments with particle sizes between 4.75 and $9.50 \mathrm{~mm}$, the ejection rates of several fragments were measured, and the average value was taken as the ejection rate. For the fragments with particle sizes less than $4.75 \mathrm{~mm}$, the rates of the fragments at different locations were measured, and the average value was taken as the ejection rate. Finally, the kinetic energies of the fragments with different particle sizes were obtained from $E_{\mathrm{k}}=m v^{2} / 2$.

2.4. Method of Calculating the Elastic Strain Energy Using the Stress-Strain Curve. During the rockburst process, the tested 


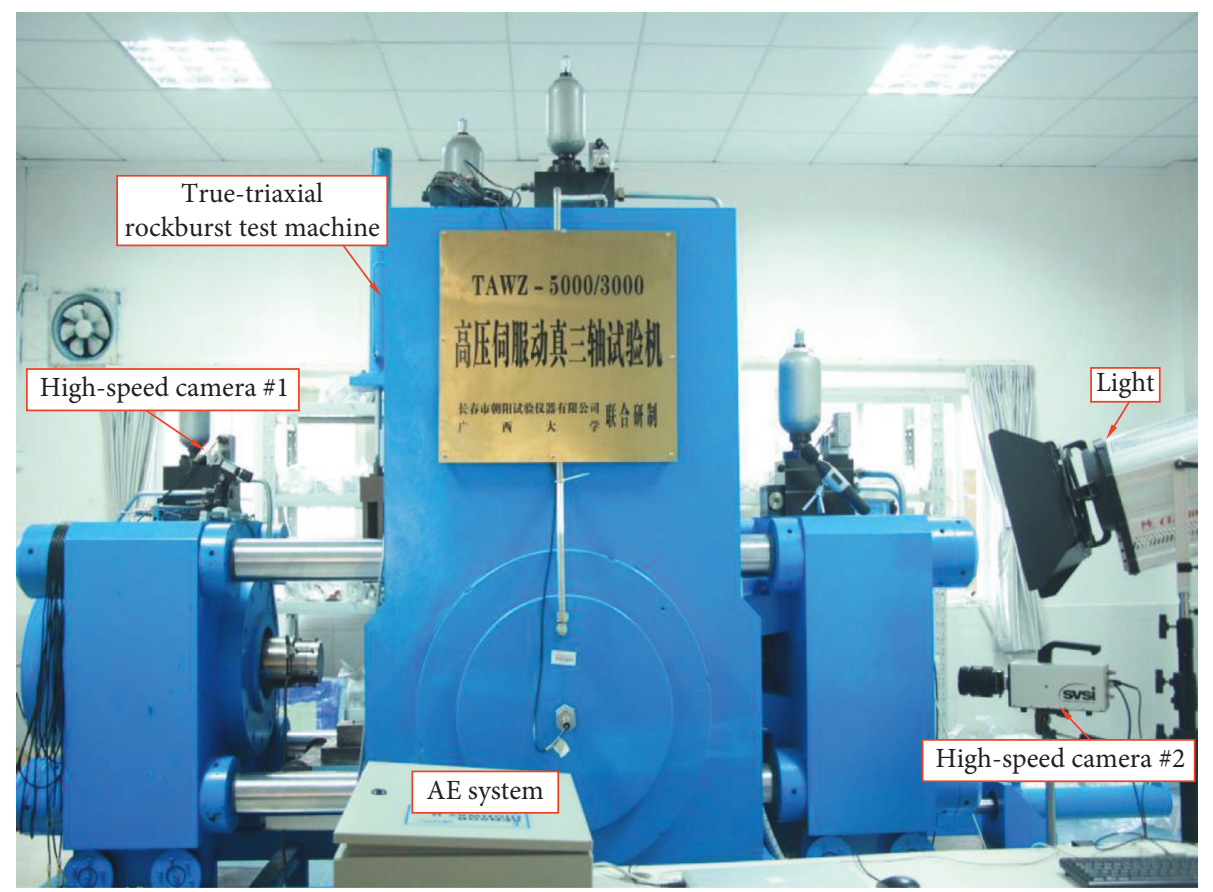

Figure 3: Illustration of the true-triaxial rockburst experimental system.

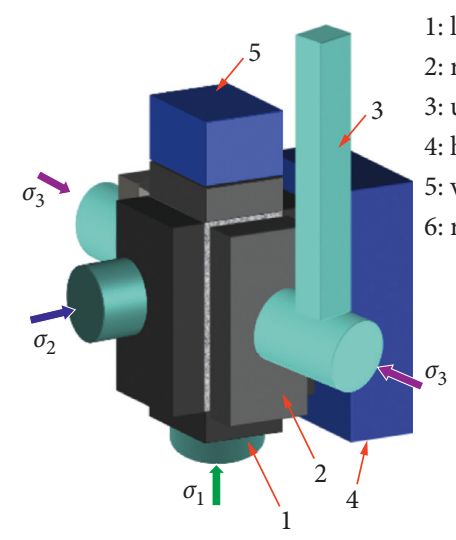

1: loading bar

2: rigid loading plate

3: unloading shaft

4: horiztioal fixed boundary

5: vertical fixed boundary

6: rock sample
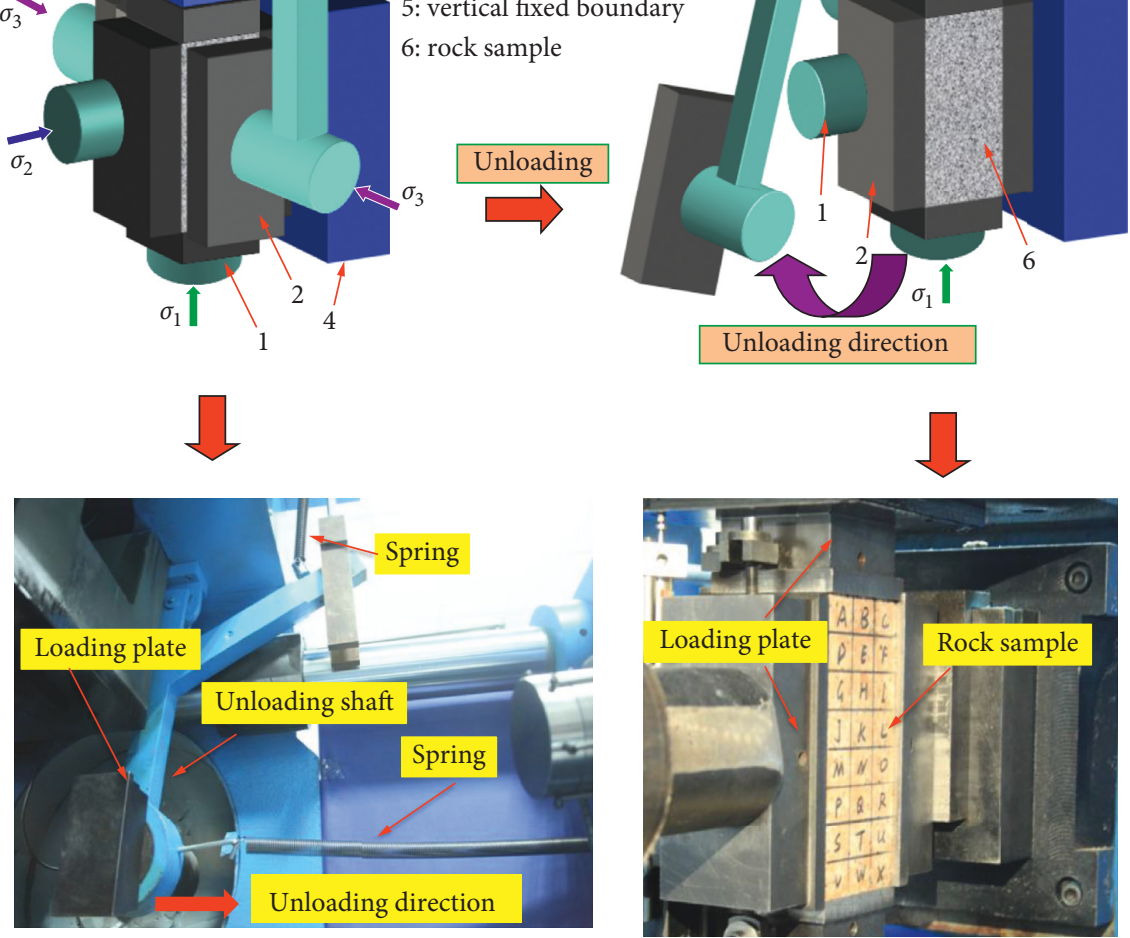

FIgUre 4: The unloading device of the test machine. 


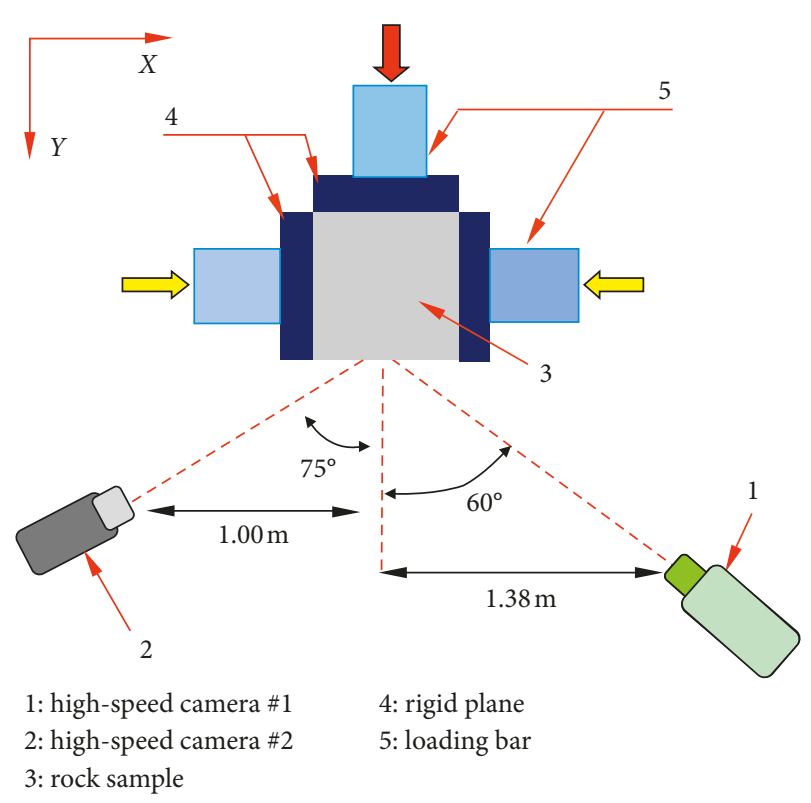

FIgURE 5: The arrangement of the high-speed camera system.

specimen experienced an energy evolutionary process that included energy accumulation, dissipation, and release. Therefore, it was feasible to investigate the rockburst mechanism based on the energy characteristics. In our study, because the horizontal stresses and strains were tiny, only the vertical strain energy was considered.

The vertical elastic strain energy was calculated according to Figure 7; the postpeak accumulated elastic energy density $u_{\mathrm{e}}$ is the area of the larger hatched triangle, and the slope of the hypotenuse of the large shaded triangle is the elastic modulus. Similarly, the residual elastic energy density $u_{\mathrm{r}}$ was also calculated according to the small shaded triangle. In addition, the postpeak released strain energy $U_{\mathrm{f}}$ of the specimen, which was calculated by

$$
U_{\mathrm{f}}=U_{\mathrm{e}}-U_{\mathrm{r}}=\left(u_{\mathrm{e}}-u_{\mathrm{r}}\right) \times V,
$$

where $U_{\mathrm{e}}$ is the prepeak accumulated energy, $U_{\mathrm{f}}$ is the released energy, $U_{\mathrm{r}}$ is the residual elastic energy, and $V$ is the volume of the corresponding specimen.

In our test, the major principal stress is much higher than the intermediate principal stress. So, the energy caused by major principal stress is much larger than that caused by intermediate principal stress. Consequently, the contribution of strain energy caused by intermediate principal stress was not considered in the present study.

2.5. Method for Analyzing the Average Size of Fragments. After the rockburst test, the recovered specimens consisted of blocks and fragments (fallen fragments and ejected fragments). In this paper, the breakage of the fragments was described by the size and quality of the fragments. The fragments were classified into four groups: coarse particles, medium grain particles, fine grain particles, and particulates using four grain size ranges, $d \geq 9.5 \mathrm{~mm}, 4.75 \mathrm{~mm} \leq d<9.5 \mathrm{~mm}, 0.075 \mathrm{~mm} \leq d<$ $4.75 \mathrm{~mm}$, and $d<0.075 \mathrm{~mm}$. The quality $m_{i}$ of the particle

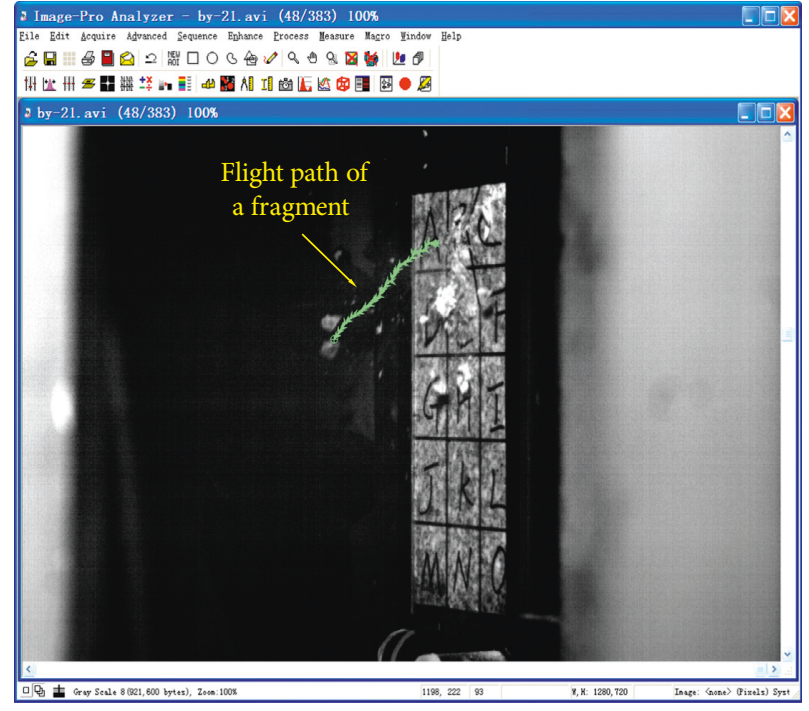

Figure 6: Analyzing the rate of the ejected fragment by using the Image ProPlus 7.0 (the average ejection rate can be calculated by $v=d / t, d$ is the length of the flight path and $t$ is the time of the flight process).

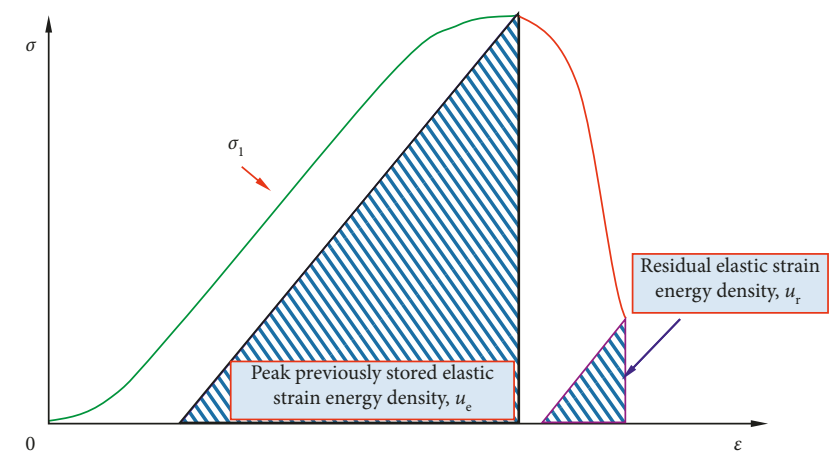

FIGURE 7: Schematic diagram of calculation of axial elastic energy density of the rock samples.

corresponding to a specific grain size $d_{i}$ (where $i$ is $1,2,3$, and 4) was also measured. The average sizes of the fragments were calculated by

$$
\bar{d}=\sum_{i=1}^{4} w_{i} \widehat{d}_{i}
$$

where

$$
w_{i}=\frac{m_{i}}{\sum m_{i}},
$$

$\bar{d}$ is the average size of the fragments of the tested specimen, $w_{i}$ is the weight, and $\widehat{d}_{i}$ is the equivalent grain size, which is determined as follows. When the grain size $d \geq 9.5 \mathrm{~mm}$, the equivalent grain size was calculated using $\widehat{d}_{i}=l_{j} / 2 \quad(i=1$, $j=1,2, \ldots, n)$, where $l_{j}$ is the maximum eigenvalue of the length, width, and thickness of fragment $j$, and when the grain size $d<9.5 \mathrm{~mm}$, the equivalent grain size was calculated using $\widehat{d}_{i}=\left(d_{m}+d_{n}\right) / 2(i=2,3,4)$, where $d_{m}$ and $d_{n}$ are the two adjacent apertures. 
As seen from the formulation (2), $\bar{d}$ is the weighted average of the equivalent grain sizes of the fragments with different grain sizes.

\section{Test Designs}

3.1. Support Failure Description. In underground excavation, support is usually used to reinforce the surrounding rock. It can improve the carrying capacity of surrounding rock by increasing the radial stress. After supporting, the tangential stress of surrounding rock will gradually increase. Upon support failure, the radial stresses of the surrounding rock on the excavated boundary vanish, and the radial stresses of the rock masses near the excavated boundary decreases to a low level. In this situation, dynamic rock failure will be induced, triggering the release of elastic strain energy, and rockburst may occur. Consequently, the effect of support failure on rockburst should be studied. In the present study, the minor principal stress $\sigma_{3}$ is used to simulate the support force.

Different supports show different deformation behaviors and strengths [26]. Support with a higher strength can provide a higher support force, leading to the surrounding rock with a higher carrying capacity. In this situation, the surrounding rock will accumulate more elastic strain energy and then show a more violent rock failure. Consequently, in the present study, the effect of support force on rockburst upon support fails is investigated.

The magnitude of the tangential stress when the support fails cannot be obtained; that is, it is difficult to foresee the timing of the support failure. In general, under the same support force (minor principal stress), the higher tangential stress when support failure causes more elastic strain energy within the rock masses, the corresponding rock failure will be more violent. Hence, the support failure timing should be studied.

Support failure is a type of unloading radial stress (minor principal stress) of the surrounding rock mass near an excavated boundary. The unloading rate of the minor principal stress significantly affects the rock failure [22, 27]. Therefore, the effect of support failure rate on rockburst will be studied in the present study.

3.2. Test Plan. As shown in Figure 8, a loading path, which can be described as loading on six surfaces and rapid unloading on one face, is designed to simulate rockburst triggered by support failure. The corresponding testing steps are presented as follows:

Step 1. Increase $\sigma_{1}, \sigma_{2}, \sigma_{3}^{\prime}$, and $\sigma_{3}$ simultaneously to the predetermined values at a loading rate of $0.3 \mathrm{MPa} / \mathrm{s}$ to simulate the redistributed stress state of the supported rock mass after excavation.

Step 2. Keep $\sigma_{1}$ and $\sigma_{2}$ constant and unload $\sigma_{3}$ with a constant rate to simulate the support failure. Once $\sigma_{3}$ decreases to $0 \mathrm{MPa}$, the corresponding loading plate is removed rapidly using an abrupt unloading device, i.e., two swing links. Meanwhile, unload $\sigma_{3}^{\prime}$ with a constant rate to a small value $(0.01 \mathrm{MPa})$ to simulate

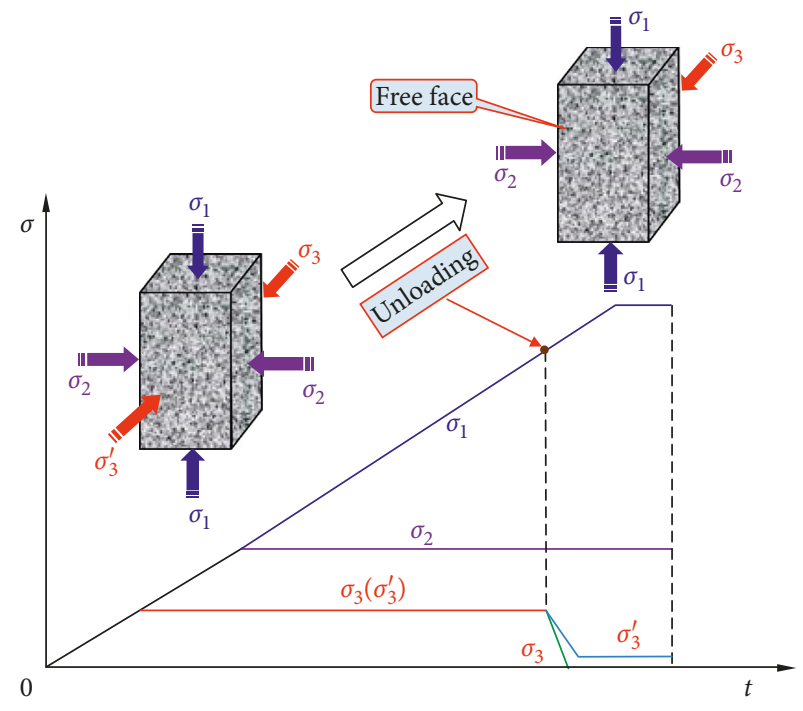

FIGURE 8: Loading path.

the decreased radial stress of the rock mass near the excavation boundary.

Step 3. After unloading $\sigma_{3}^{\prime}$ and $\sigma_{3}, \sigma_{1}$ is continually increased until the rock specimen fails. Simultaneously, the high-speed camera was used to monitor the rockburst process.

The testing plan for investigating the effect of support force on rockburst is presented in Table $1 . \sigma_{1}$, when the minimum principal stress is unloaded, is determined using the AE system. Once the AE hits drops to a low level and keeps constant for a short time, we believed that the specimen was entering a critical rockburst state. The corresponding maximum principal stress is taken as $\sigma_{1}$ when the support fails (unloading the minimum principal stress). The unloading rate of both $\sigma_{3}^{\prime}$ and $\sigma_{3}$ is $0.5 \mathrm{MPa} / \mathrm{s}$.

The testing plan for investigating the effect of support failure timing on rockburst is presented in Table 2. To develop a reasonable test plan for simulating rockbursts induced by support failure, a true-triaxial compression test with $\sigma_{2}$ of $30 \mathrm{MPa}$ and $\sigma_{2}$ of $30 \mathrm{MPa}$ is conducted. The corresponding maximum compression stress $\sigma_{\mathrm{s}}$ is $259 \mathrm{MPa}$. The support failure at different $\sigma_{1}$ condition is used to simulate the different support failure timing. In the present study, three $\sigma_{1}\left(50 \% \sigma_{s}, 77 \% \sigma_{s}\right.$, and $\left.90 \% \sigma_{s}\right)$ were designed. The unloading rate of both $\sigma_{3}^{\prime}$ and $\sigma_{3}$ is $0.5 \mathrm{MPa} / \mathrm{s}$.

The testing plan for investigating the effect of support failure rate on rockburst is presented in Table 3. Four support failure rates (unloading rates of both $\sigma_{3}^{\prime}$ and $\sigma_{3}$ ), 0.1, $0.5,1.0$, and $2.0 \mathrm{MPa} / \mathrm{s}$, were designed. The predetermined $\sigma_{1}, \sigma_{2}$, and $\sigma_{3}$ (support force) were 260,30 , and $3 \mathrm{MPa}$, respectively.

\section{Test Results}

4.1. Influence of Support Forces on Rockbursts. The test results are shown in Table 4, and Figures 9-13 are analyzed in detail as follows. 
TABLE 1: Testing plan of one-single face true-triaxial unloading test under the true-triaxial condition with different support forces.

\begin{tabular}{lccc}
\hline Specimen number & $\sigma_{2}(\mathrm{MPa})$ & $\sigma_{3}$ (support forces) $(\mathrm{MPa})$ & Unloading rate $(\mathrm{MPa} / \mathrm{s})$ \\
\hline GZ-1 & 30 & 0.1 & 0.5 \\
GZ-2 & 30 & 1 & 0.5 \\
GZ-3 & 30 & 3 & 0.5 \\
\hline
\end{tabular}

TABLE 2: Testing plan of one-single face true-triaxial unloading test with different support failure timings.

\begin{tabular}{lcccc}
\hline Specimen number & $\sigma_{1 /} \sigma_{\mathrm{s}}(\%)$ & $\sigma_{2}(\mathrm{MPa})$ & $\sigma_{3}(\mathrm{MPa})$ & Unloading rate $(\mathrm{MPa} / \mathrm{s})$ \\
\hline GZ-4 & 50 & 30 & 3 & 0.5 \\
GZ-5 & 77 & 30 & 3 & 0.5 \\
GZ-3 & 90 & 30 & 3 & 0.5 \\
\hline
\end{tabular}

TABLE 3: Testing plan of one-single face true-triaxial unloading test with different support failure rates.

\begin{tabular}{lcccc}
\hline $\begin{array}{l}\text { Specimen } \\
\text { number }\end{array}$ & $\begin{array}{c}\sigma_{1} \\
(\mathrm{MPa})\end{array}$ & $\begin{array}{c}\sigma_{2} \\
(\mathrm{MPa})\end{array}$ & $\begin{array}{c}\sigma_{3} \\
(\mathrm{MPa})\end{array}$ & $\begin{array}{c}\text { Failure } \\
\text { rate }(\mathrm{MPa} / \mathrm{s})\end{array}$ \\
\hline GZ-6 & 260 & 30 & 3 & 0.1 \\
GZ-7 & 260 & 30 & 3 & 0.5 \\
GZ-8 & 260 & 30 & 3 & 1.0 \\
GZ-9 & 260 & 30 & 3 & 2.0 \\
\hline
\end{tabular}

(1) The rockburst processes on the free faces of the different rock specimens recorded using the high-speed cameras are shown in Figures 9(a)-9(c). It is clear that all the rock specimens experienced similar failure processes, i.e., particle ejections, spalling failure, and fragment ejection as soon as the rock plate broke off. Under the high support force $\left(\sigma_{3}=3 \mathrm{MPa}\right)$ condition, the failure region and the speed of ejected fragments are larger than those under the low support force $\left(\sigma_{3}=0.1 \mathrm{MPa}\right)$ condition. Consequently, it can be concluded that the tested specimen under high support force shows a more violent rockburst process than that under low support force.

(2) The fractured rock specimens after the rockbursts are shown in Figures 10 (a)-10(c). It is obvious that the $\mathrm{V}$-shaped rockburst notches appeared near the free faces. The dimensions (length, width, and depth) of the rockburst notches with the support forces of 0.1 , 1.0 , and $3.0 \mathrm{MPa}$ are $10.2 \mathrm{~cm} \times 10.0 \mathrm{~cm} \times 1.6 \mathrm{~cm}$, $15.1 \mathrm{~cm} \times 10.0 \mathrm{~cm} \times 2.1 \mathrm{~cm}$, and $15.2 \mathrm{~cm} \times 10.0 \mathrm{~cm} \times$ $2.3 \mathrm{~cm}$, respectively. These dimensions show that the depth of the rockburst notch increases with the increasing support force. In addition, it also can be seen that under high support force (3 MPa), the shear fractures away are more obvious than those under low support force (0.1 MPa).

(3) The average sizes of the fragments after the rockbursts can be observed in Table 4 . The average size of the fragments under the condition of a $3 \mathrm{MPa}$ support force was $60.13 \mathrm{~mm}$, which was approximately $73.56 \%$ and $58.62 \%$ larger than that with support forces of 1.0 and $0.1 \mathrm{MPa}$. The size distributions and quality percentages of the fragments are presented in Figure 11. The shapes of the coarse fragments $(d \geq 9.5 \mathrm{~mm})$, medium fragments $(4.75 \leq d<$ $9.5 \mathrm{~mm})$, fine fragments $(0.075 \mathrm{~mm} \leq d<4.75 \mathrm{~mm})$, and tiny fragments were plate, flake, sand, and power, respectively. It can be observed that the quality percentages of the coarse particles exceeded $80 \%$, and the quality percentage of the ejected coarse particles under the condition of a $3 \mathrm{MPa}$ support force was the largest.

(4) The kinetic energies of the ejected fragments are listed in Table 4 . The qualities, average rates, and kinetic energies of the ejected fragments increased as the support force was incremented. The kinetic energy of the ejected fragment under a support force of $3 \mathrm{MPa}$ condition is about $723.1 \%$ larger than that under a support force of $0.1 \mathrm{MPa}$ condition.

(5) The stress-strain curves are shown in Figure 12, it can be observed that the critical state stress close to the peak strength of the specimen with a support force of $3 \mathrm{MPa}$ was $244 \mathrm{MPa}$, which was approximately $2.5 \%$ and $10.9 \%$ larger than those with confining pressures of 1 and $0.1 \mathrm{MPa}$. Thus, the critical state stress close to peak strength increased as the confining pressure increased. In addition, the prepeak stress-strain curve slopes of specimens GZ-2 and GZ-3, with larger support forces, were obviously larger than that of specimen GZ-1, with a smaller support force.

(6) As shown in Figure 13, for the tested specimens with support forces of $0.1,1.0$, and $3.0 \mathrm{MPa}$, the prepeak accumulative energies were $1017.22 \mathrm{~J}, 1389.19 \mathrm{~J}$, and $1591.22 \mathrm{~J}$, and the postpeak released strain energies were $957.42 \mathrm{~J}, 1298.85 \mathrm{~J}$, and $1495.12 \mathrm{~J}$. As the support force increased, the prepeak accumulative energy increased. This indicates that upon support fails, larger support forces will trigger more violent rockbursts.

4.2. Influence of Support Failure Timings on Rockbursts. The test results are shown in Table 5 and Figures 14-18 and are analyzed in detail as follows:

(1) The rockburst processes on the free faces of the rock specimens are shown in Figure 14. All the rock specimens experienced the similar failure processes, i.e., particle ejection, spalling failure, and fragment ejection as soon as the rock plate broke off. Under high major principal stress $\left(\sigma_{3}=233 \mathrm{MPa}, 90 \% \sigma_{\mathrm{s}}\right)$ 
TABLE 4: Testing results of one-single face true-triaxial unloading test with different support forces.

\begin{tabular}{|c|c|c|c|c|c|c|c|c|}
\hline $\begin{array}{l}\text { Specimen } \\
\text { number }\end{array}$ & $\begin{array}{c}\text { Support } \\
\text { force }(\mathrm{MPa})\end{array}$ & $\begin{array}{c}\sigma_{1} \text { when } \\
\text { unloading } \\
\sigma_{3}(\mathrm{MPa})\end{array}$ & $\begin{array}{c}\sigma_{\max } \\
(\mathrm{MPa})\end{array}$ & $\begin{array}{c}\text { Dimension } \\
\text { of the rockburst } \\
\text { notch } \\
(\mathrm{cm} \times \mathrm{cm} \times \mathrm{cm})\end{array}$ & $\begin{array}{c}\text { Mass of } \\
\text { ejected } \\
\text { fragments }(\mathrm{g})\end{array}$ & $\begin{array}{c}\text { Average rate of } \\
\text { ejected } \\
\text { fragments }(\mathrm{m} / \mathrm{s})\end{array}$ & $\begin{array}{c}\text { Kinetic } \\
\text { energy of ejected } \\
\text { fragments }(\mathrm{J})\end{array}$ & $\begin{array}{c}\text { Average } \\
\text { size of ejected } \\
\text { fragments } \\
(\mathrm{mm})\end{array}$ \\
\hline GZ-1 & 0.1 & 181.1 & 202 & $10.2 \times 10.0 \times 1.6$ & 71.19 & 3.31 & 0.39 & 34.65 \\
\hline GZ-2 & 1 & 199.8 & 236 & $15.1 \times 10.0 \times 2.1$ & 272.63 & 3.87 & 2.04 & 37.92 \\
\hline GZ-3 & 3 & 233.1 & 244 & $15.2 \times 10.0 \times 2.3$ & 283.14 & 4.76 & 3.21 & 60.13 \\
\hline
\end{tabular}
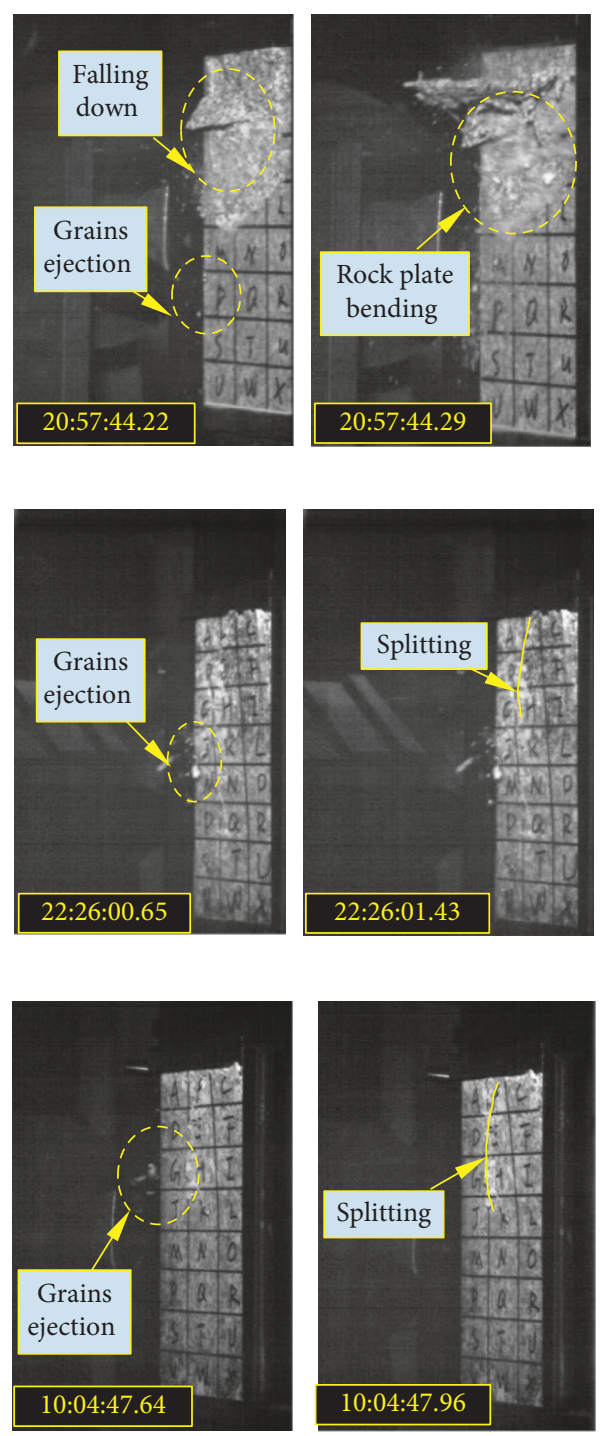
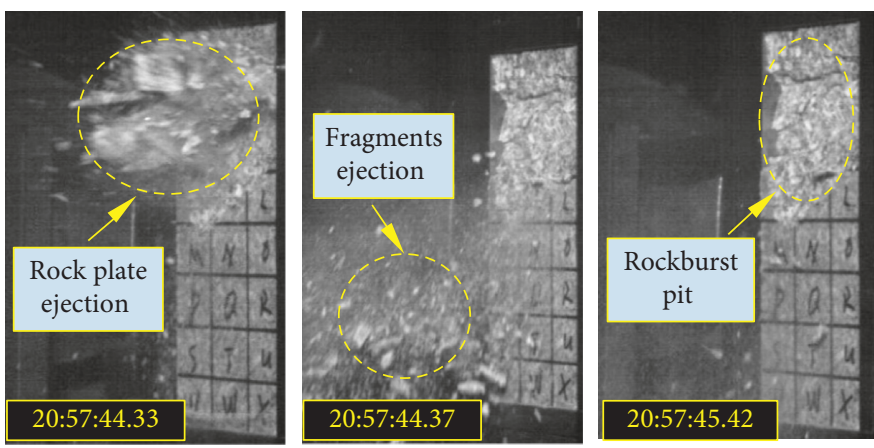

(a)
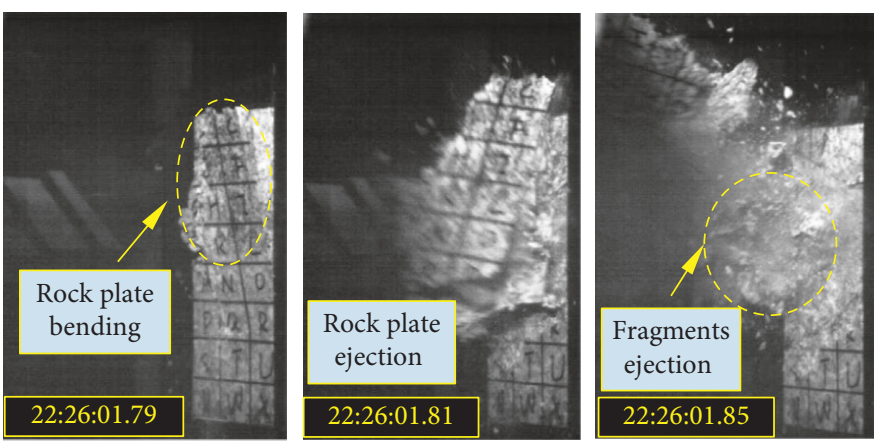

(b)
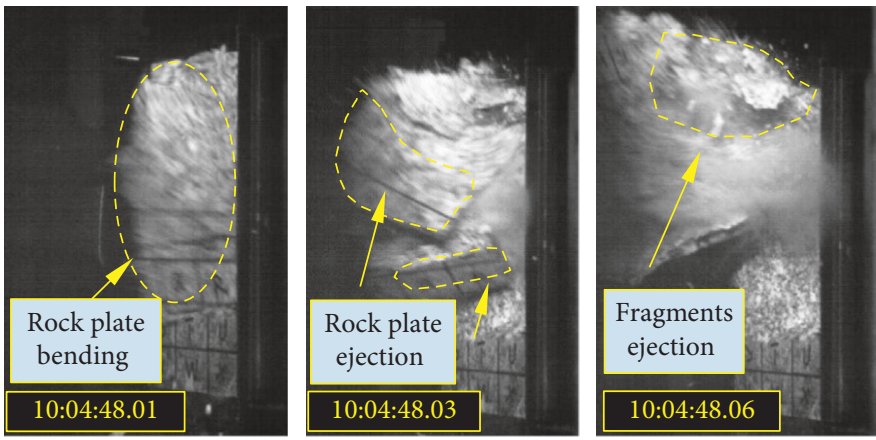

(c)

FIGURE 9: The rockburst process of the tested specimens under different support forces (the numbers at bottom-left corner of the pictures indicate the time in h:m:s.ms): (a) $\sigma_{3}=0.1 \mathrm{MPa}$; (b) $\sigma_{3}=1 \mathrm{MPa}$; (c) $\sigma_{3}=3 \mathrm{MPa}$.

when support fails, the failure region and the speed of ejected fragments are larger than those under low support force $\left(\sigma_{3}=160 \mathrm{MPa}, 50 \% \sigma_{\mathrm{s}}\right)$ condition. Consequently, it can be concluded that the later the support fails, the more violent the rockburst process is.

(2) Figure 15 shows the failure forms of the fractured specimens under different support failure timing. It can be seen that under high support force (3 MPa), the shear fractures away are more obvious than those under low support force (0.1 MPa)

(3) As shown in Table 5, the average size of the fragments under the condition of the support failing later $\left(\sigma_{1} / \sigma_{\max }=90 \%\right)$ was $60.13 \mathrm{~mm}$, which was approximately $73.56 \%$ and $58.57 \%$ larger than those under the condition of earlier support failure $\left(\sigma_{1} / \sigma_{\max }=50 \%\right.$ and $\left.77 \%\right)$. The size distributions 


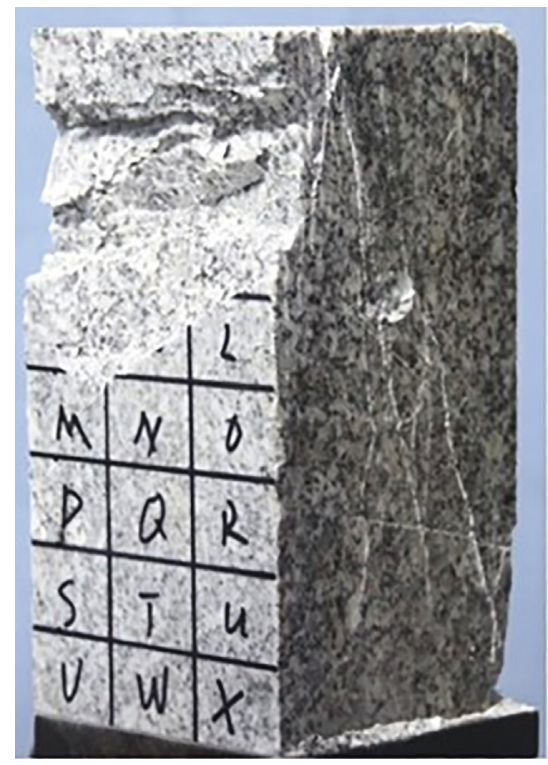

(a)

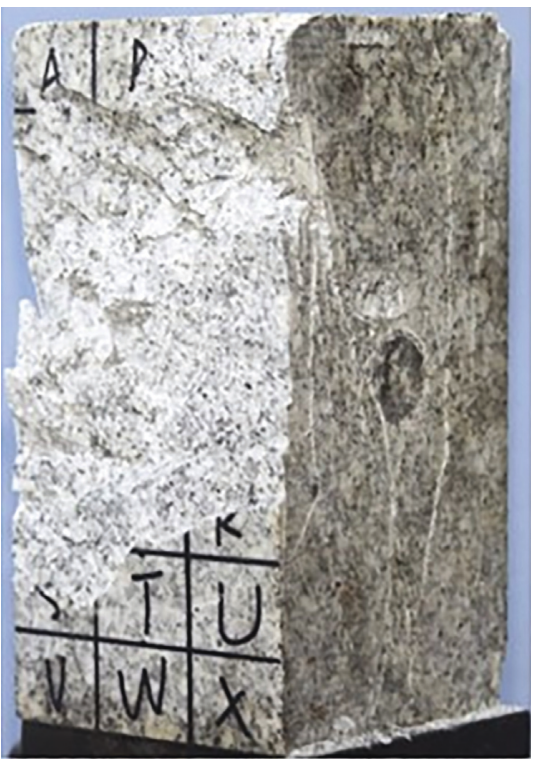

(b)

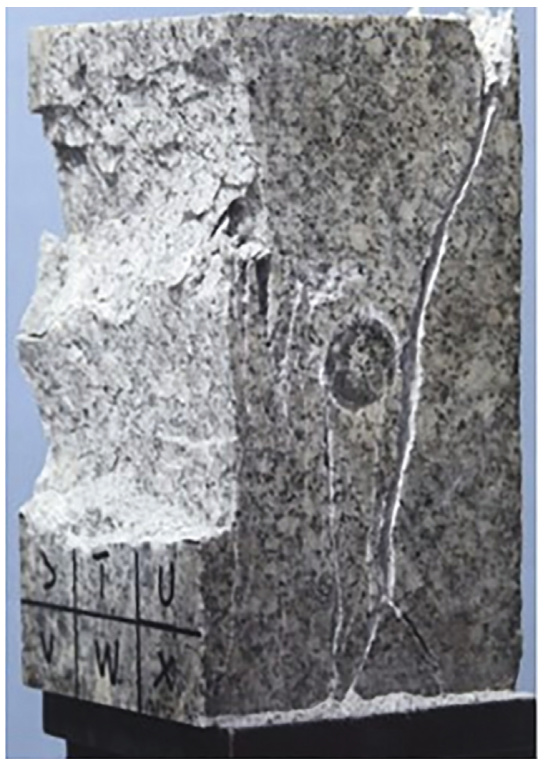

(c)

Figure 10: The failure form of the tested specimens under different support forces: (a) $\sigma_{3}=0.1 \mathrm{MPa}$; (b) $\sigma_{3}=1 \mathrm{MPa}$; (c) $\sigma_{3}=3 \mathrm{MPa}$.

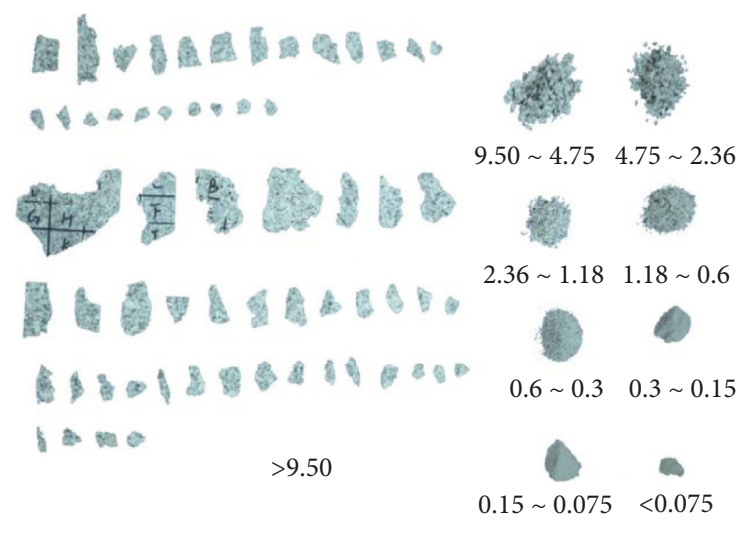

(a)
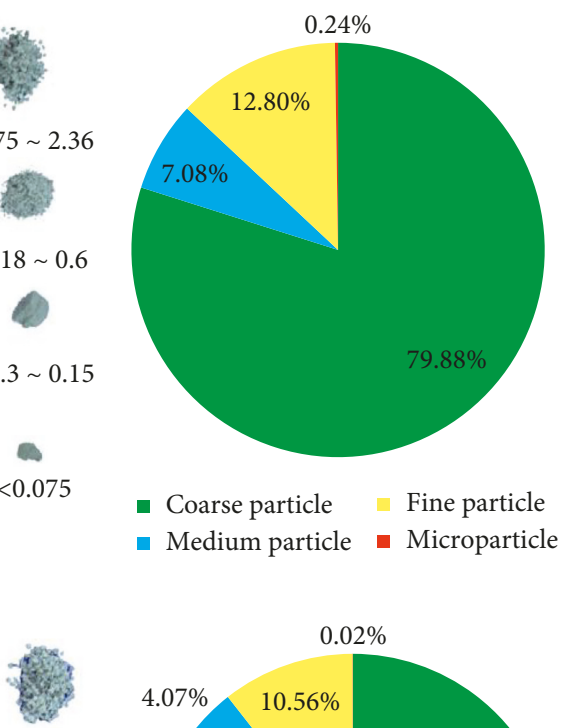

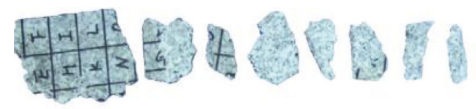

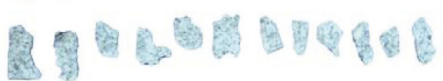

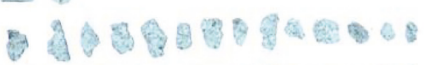

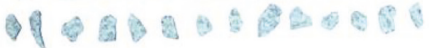

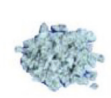

$9.50 \sim 4.75$

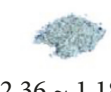

$4.75 \sim 2.36$

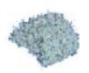

900 중

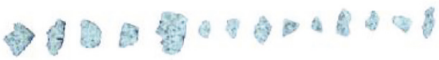

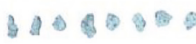

$>9.50$

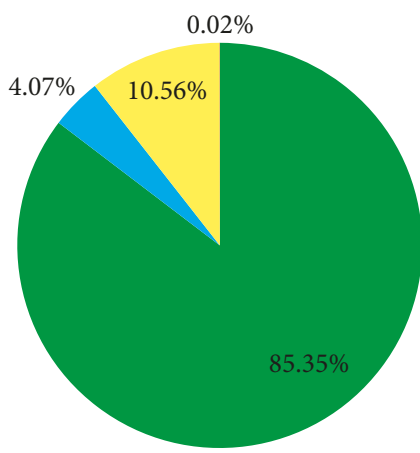

- Medium particle - Microparticle
$2.36 \sim 1.18 \quad 1.18 \sim 0.6$
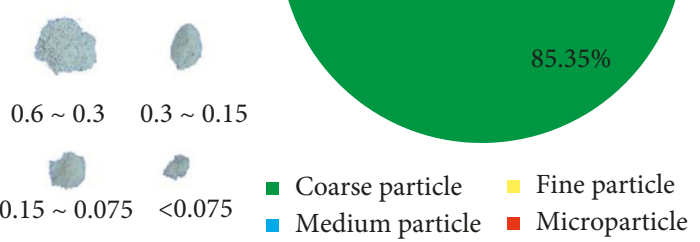

(b)

Figure 11: Continued. 


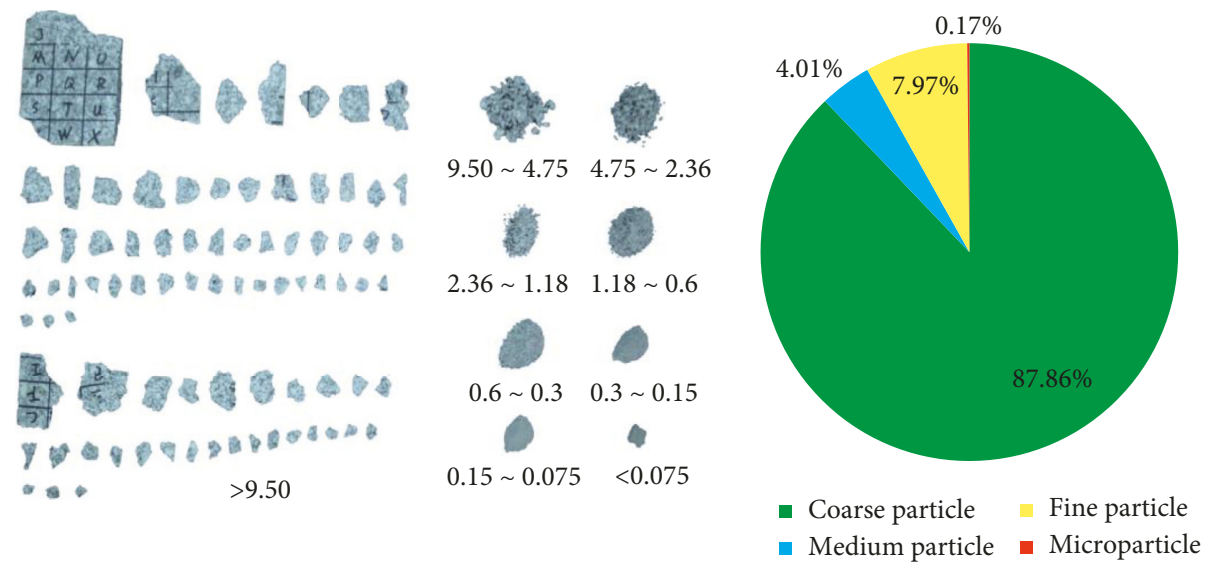

(c)

FIGURE 11: The size distribution of the fragments under different support forces (unit: $\mathrm{mm}$ ): (a) $\sigma_{3}=0.1 \mathrm{MPa}$; (b) $\sigma_{3}=1 \mathrm{MPa}$; (c) $\sigma_{3}=3 \mathrm{MPa}$.

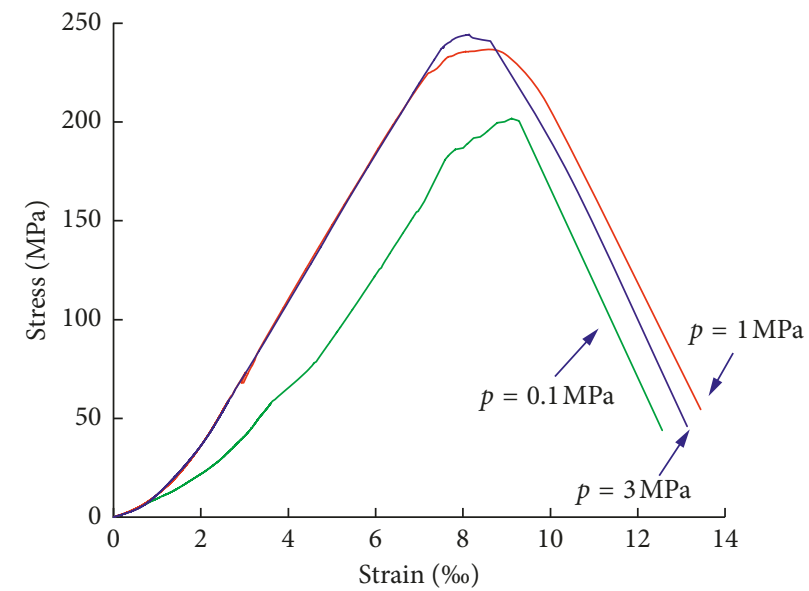

FiguRE 12: The axial stress-strain curve of the tested specimens under different support forces.

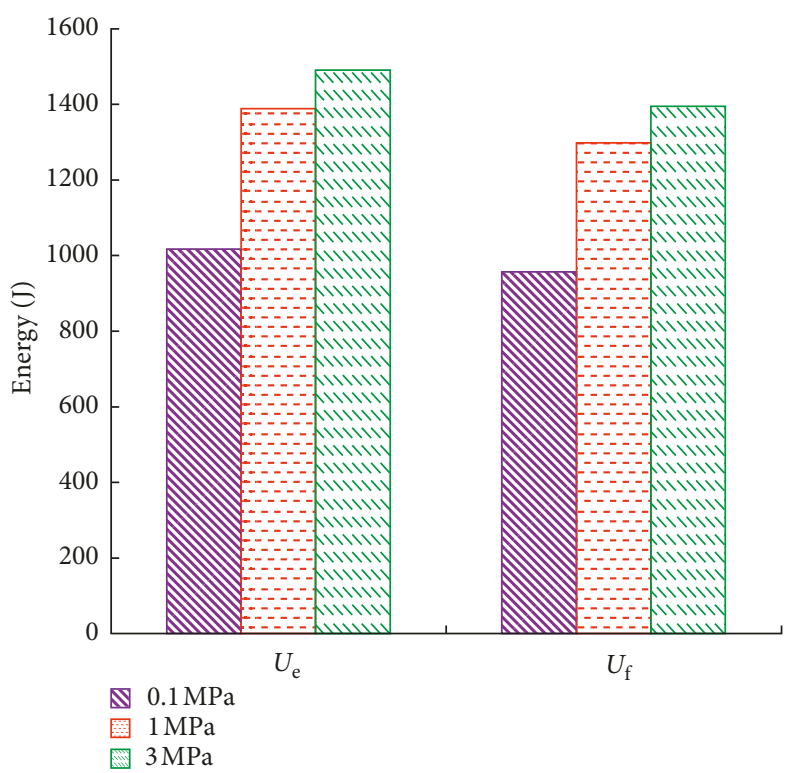

Figure 13: Comparison of the elastic strain energy under different support forces $\left(U_{\mathrm{e}}\right.$ is the accumulated elastic strain energy before rock failure and $U_{\mathrm{f}}$ is the released energy after rock failure). 
TABLE 5: Testing results of one-single face true-triaxial unloading test under the true-triaxial condition with different support failure timings.

\begin{tabular}{lcccccc}
\hline $\begin{array}{l}\text { Specimen } \\
\text { number }\end{array}$ & $\begin{array}{c}\sigma_{\max } \\
(\mathrm{MPa})\end{array}$ & $\begin{array}{c}\text { Dimension of } \\
\text { rockburst notch } \\
(\mathrm{cm} \times \mathrm{cm} \times \mathrm{cm})\end{array}$ & $\begin{array}{c}\text { Quality of } \\
\text { ejected } \\
\text { fragments }(\mathrm{g})\end{array}$ & $\begin{array}{c}\text { Average rate of } \\
\text { ejected fragments } \\
(\mathrm{m} / \mathrm{s})\end{array}$ & $\begin{array}{c}\text { Kinetic energy } \\
\text { of ejected } \\
\text { fragments }(\mathrm{J})\end{array}$ & $\begin{array}{c}\text { Average size } \\
\text { of ejected } \\
\text { fragments }(\mathrm{mm})\end{array}$ \\
\hline GZ-4 & 183 & $15.8 \times 10.0 \times 1.7$ & 70.13 & 3.33 & 0.39 & 38.65 \\
GZ-5 & 205 & $17.5 \times 10.0 \times 1.6$ & 272.44 & 3.24 & 1.43 & 3.21 \\
GZ-3 & 244 & $15.2 \times 10.0 \times 2.3$ & 283.14 & 4.76 & 60.13 \\
\hline
\end{tabular}
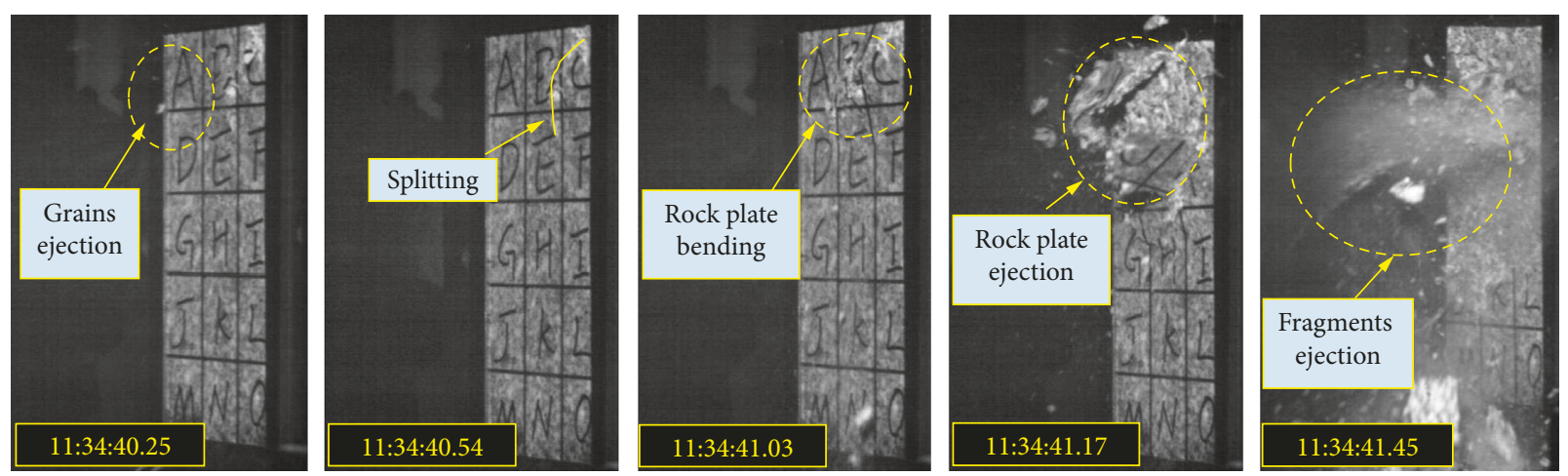

(a)
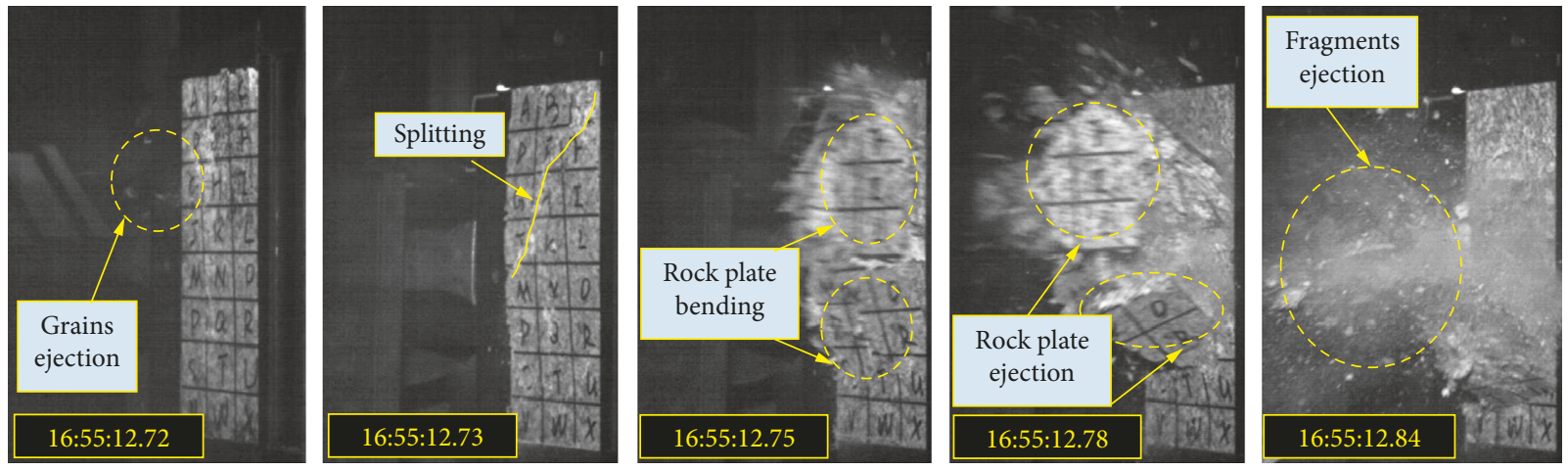

(b)
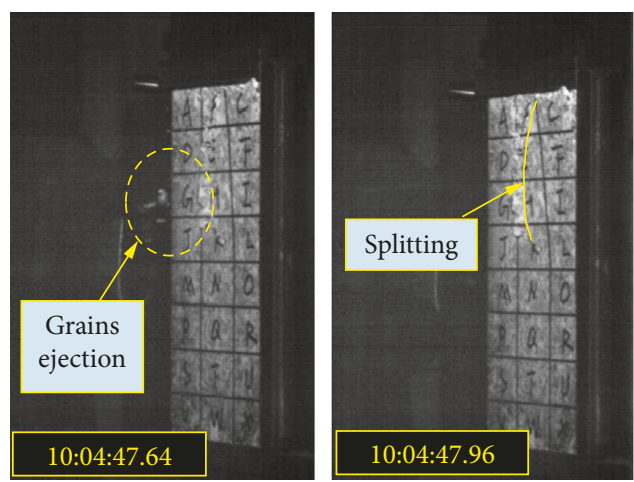
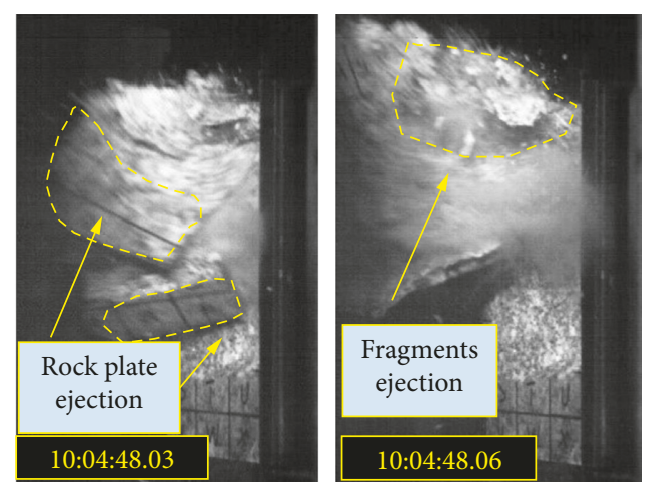

(c)

Figure 14: The rockburst process of the tested specimens under different support failure timings (the numbers at the bottom-left corner of the pictures indicate the time in h:m:s.ms): (a) $\sigma_{1} / \sigma_{\max }=50 \%$; (b) $\sigma_{1} / \sigma_{\max }=77 \%$; (c) $\sigma_{1} / \sigma_{\max }=90 \%$.

and mass percentages of the fragments can be observed in Figure 16, and it is clear that the mass percentages of the coarse particles were always larger than $79 \%$.
(4) The kinetic energies of the ejected fragments of the test specimens are listed in Table 5. The kinetic energies of the ejected fragments under the condition of later support failed $\left(\sigma_{1} / \sigma_{\max }=77 \%\right.$ and $\left.90 \%\right)$ were 


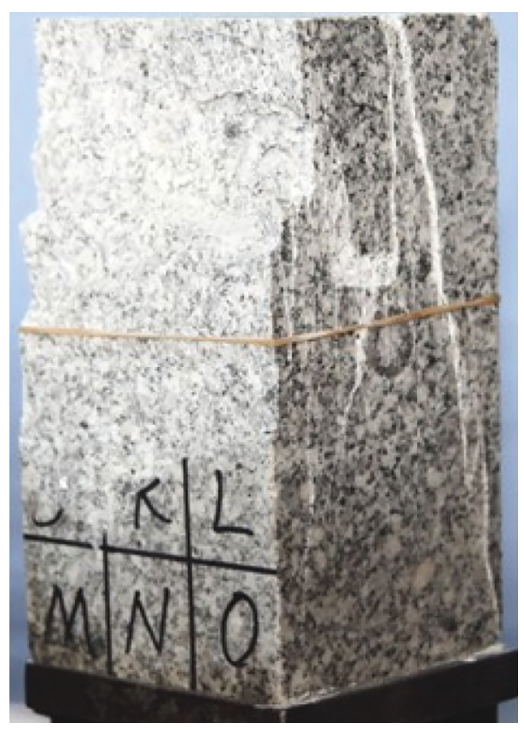

(a)

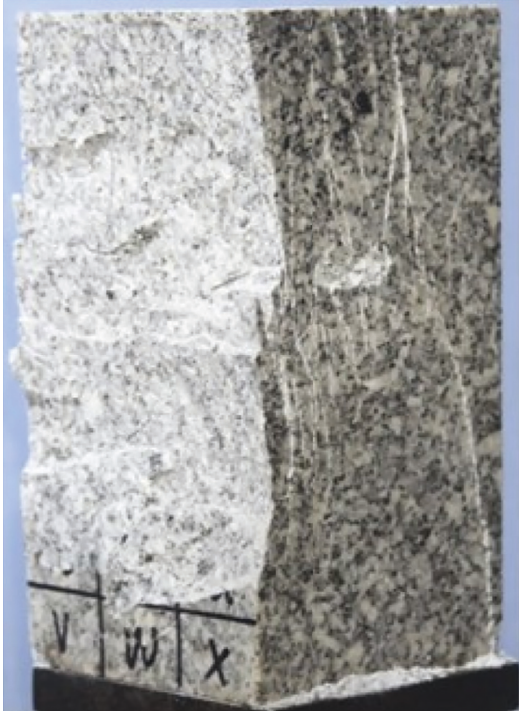

(b)

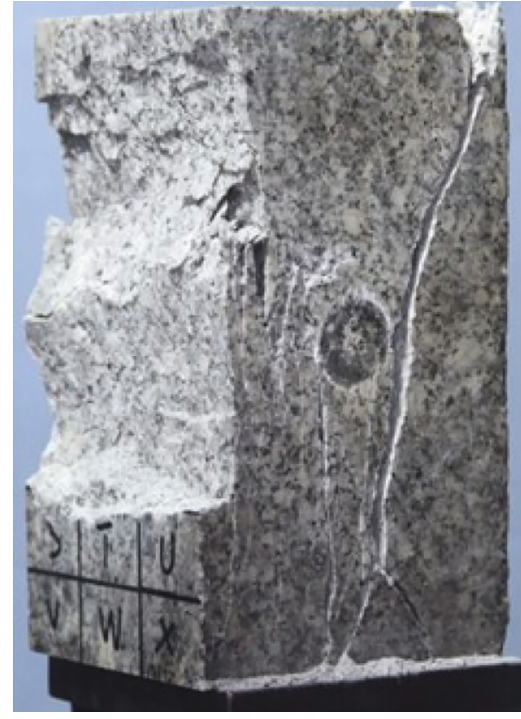

(c)

Figure 15: The failure form of the tested specimens under different support failure timings: (a) $\sigma_{1} / \sigma_{\max }=50 \%$; (b) $\sigma_{1} / \sigma_{\max }=77 \%$; (c) $\sigma_{1} / \sigma_{\max }=90 \%$.

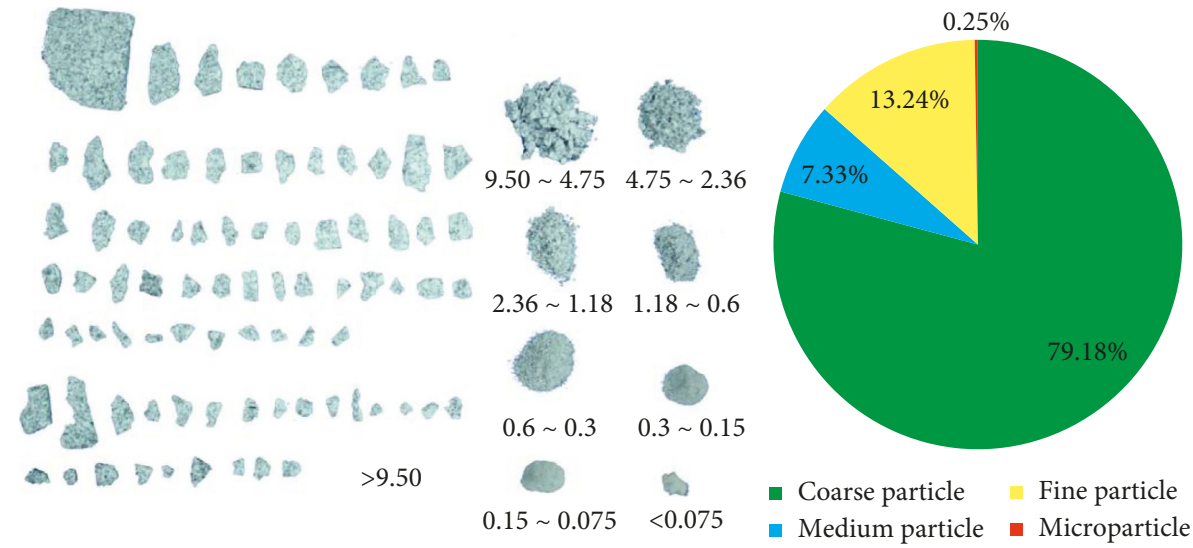

(a)

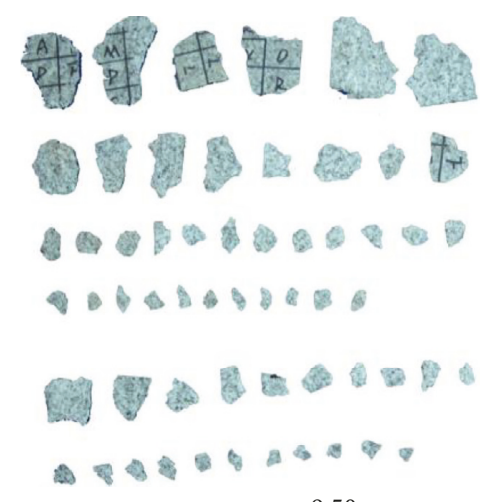

$>9.50$

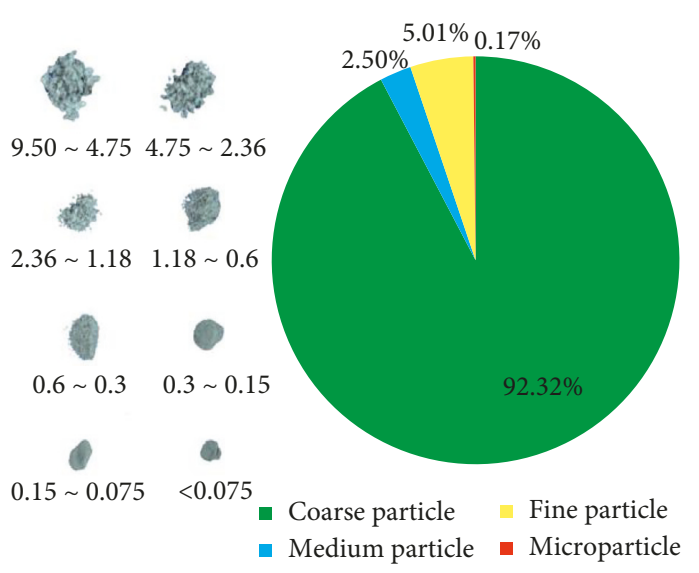

(b)

Figure 16: Continued. 

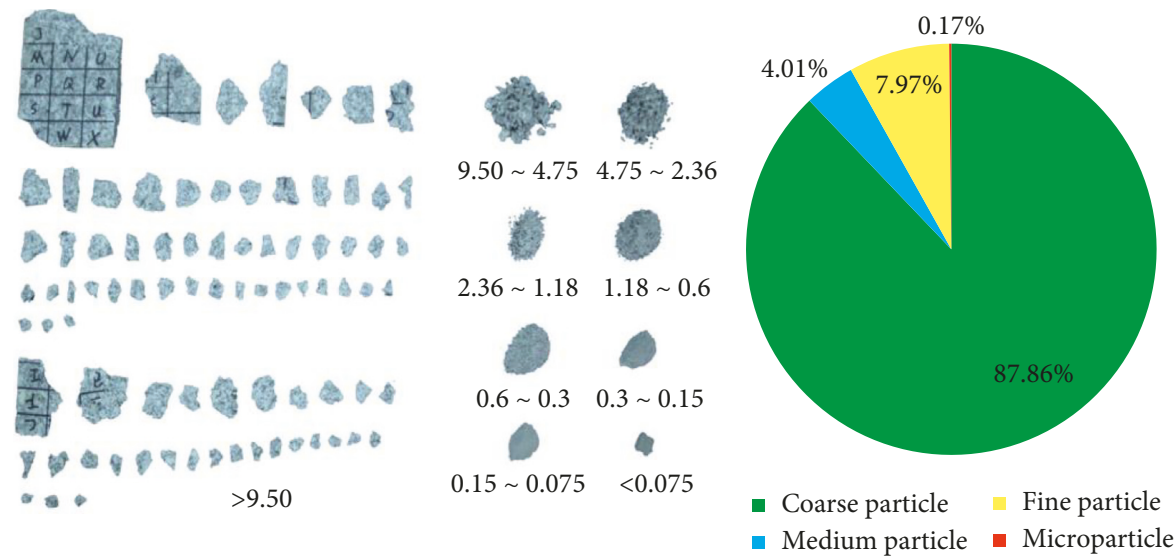

(c)

Figure 16: The size distribution of the fragments under different support failure timings (unit: mm): (a) $\sigma_{1} / \sigma_{\max }=50 \%$; (b) $\sigma_{1} / \sigma_{\max }=77 \%$; (c) $\sigma_{1} / \sigma_{\max }=90 \%$.

approximately $266.7 \%$ and $723.1 \%$ larger than that under the condition of earlier support failure $\left(\sigma_{1} / \sigma_{\max }=50 \%\right)$. In short, the later the support failed, the larger the qualities, average rates, and kinetic energies of the ejected fragments.

(5) The stress-strain curves under different support failure timings are shown in Figure 17. In the case of $\sigma_{1} / \sigma_{\max }$ of $90 \%$, the vertical strain was $13.13 \%$, which was $8.0 \%$ and $11.9 \%$ larger than those under conditions of $\sigma_{1} / \sigma_{\max }$ of $77 \%$ and $50 \%$. This indicates that the later the support fails, the larger the vertical strain before rock failure is.

(6) The prepeak accumulative energies and postpeak released strain energies under different support failure timings are shown in Figure 18. The prepeak accumulative energies were $1008.32 \mathrm{~J}, 1044.37 \mathrm{~J}$, and $1491.12 \mathrm{~J}$, and the postpeak released strain energies were $778.18 \mathrm{~J}, 976.88 \mathrm{~J}$, and $1395.42 \mathrm{~J}$ under conditions of $\sigma_{1} / \sigma_{\max }$ of $50 \%, 77 \%$, and $90 \%$. In short, the later the support failed, the greater the prepeak accumulative strain energies and the postpeak released energies were, which led to more intensive rockbursts.

4.3. Influence of Support Failure Rates on Rockbursts. The test results are shown in Table 6 and Figures 19-22. It should be noted that the rock specimen failed immediately after unloading $\sigma_{3}$. Therefore, the maximum major principal stress is the predetermined major principal stress $(260 \mathrm{MPa})$. The test results are analyzed in detail as follows:

(1) As shown in Figure 19, the specimen, subjected to a support failure rate of $0.1 \mathrm{MPa} / \mathrm{s}$, exhibited static brittle failure without fragment ejection. In this case, the failure process of the free face could not be captured because the specimen failed before the loading plate was completely drawn away. For specimens with support failure rates of $0.5,1.0$, and $2.0 \mathrm{MPa} / \mathrm{s}$, respectively, their failure presented

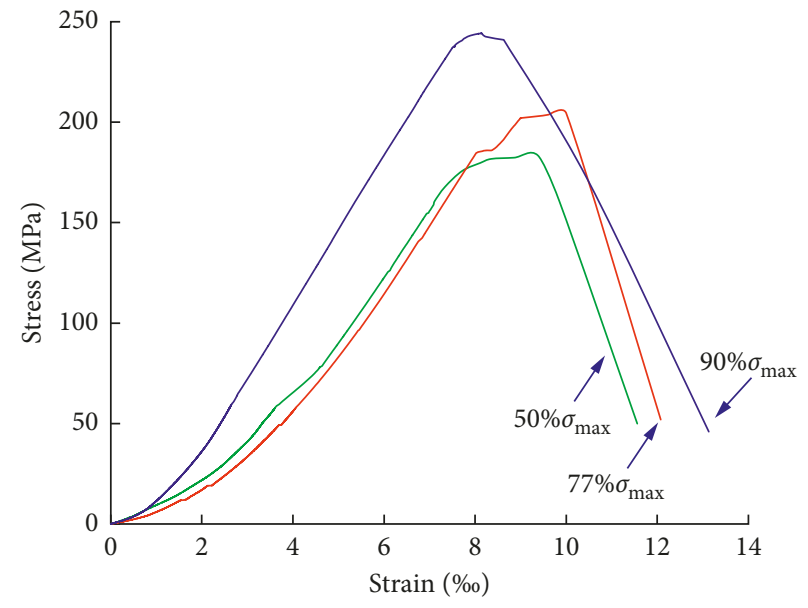

FIGURE 17: The axial stress-strain curve of the tested specimens under different support failure timings.

rockburst behaviors. As the support failure rate increases from $0.1 \mathrm{MPa} / \mathrm{s}$ to $3.0 \mathrm{MPa} / \mathrm{s}$, the failure mode of the tested specimens changed from static brittle failure to dynamic rockbursts. Another finding from these figures is that the duration time of the rockburst process, from particle ejection to overall failure, decreased with the increasing support failure rate.

(2) The fractured rock specimens after the test are shown in Figure 20. It is obvious that the failure form of the specimen with a support failure rate of $0.1 \mathrm{MPa} / \mathrm{s}$ was dominated by splitting cracks and shearing cracks. For the specimens with the support failure rates of $0.5,1.0$, and $2.0 \mathrm{MPa} / \mathrm{s}$, in addition to the splitting cracks and shearing cracks, V-shaped rockburst notches can be observed near the free faces of specimens. The dimensions (lengths, widths, and depths) of the rockburst notches were $7.5 \mathrm{~cm} \times 10.0 \mathrm{~cm} \times 1.5 \mathrm{~cm}, \quad 13.3 \mathrm{~cm}$ $\times 10.0 \mathrm{~cm} \times 1.6 \mathrm{~cm}$, and $15.0 \mathrm{~cm} \times 10.0 \mathrm{~cm} \times 2.0 \mathrm{~cm}$, respectively, indicating that the dimensions of the 


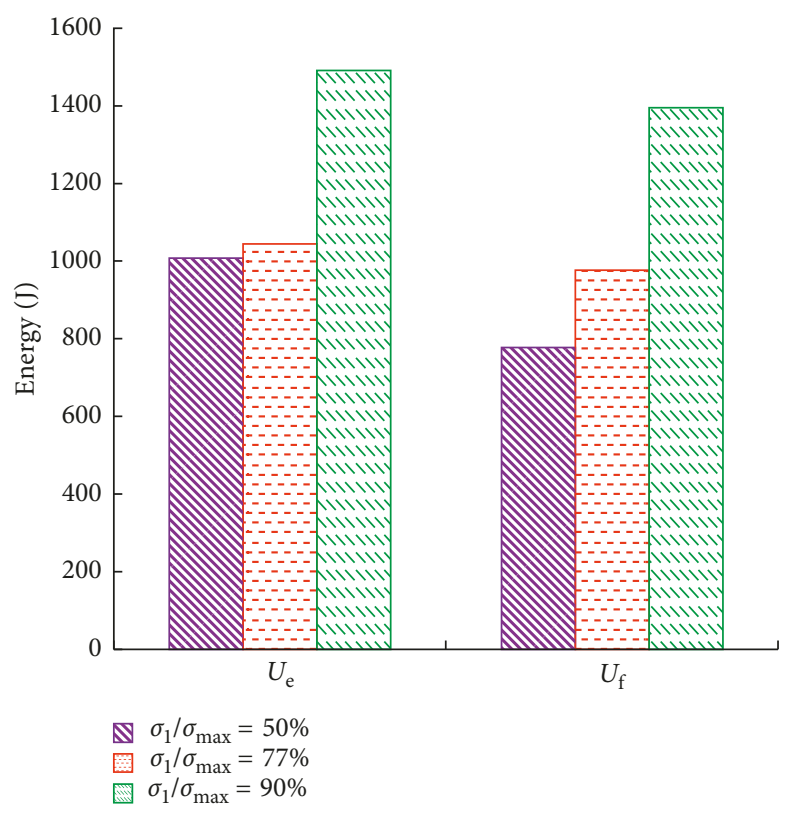

Figure 18: The comparison of the elastic strain energy under different support failure timings.

TABLE 6: Testing results of one-single face true-triaxial unloading test with different support failure rates.

\begin{tabular}{|c|c|c|c|c|c|c|}
\hline $\begin{array}{l}\text { Specimen } \\
\text { number }\end{array}$ & $\begin{array}{l}\text { Unloading } \\
\text { rate of } \sigma_{3} \\
(\mathrm{MPa} / \mathrm{s})\end{array}$ & $\begin{array}{c}\text { Dimension } \\
\text { of rockburst notch } \\
(\mathrm{cm} \times \mathrm{cm} \times \mathrm{cm})\end{array}$ & $\begin{array}{l}\text { Quality of the ejected } \\
\text { fragments }(\mathrm{g})\end{array}$ & $\begin{array}{l}\text { Average rate of } \\
\text { ejected fragments } \\
(\mathrm{m} / \mathrm{s})\end{array}$ & $\begin{array}{c}\text { Kinetic energy of } \\
\text { ejected fragments }(\mathrm{J})\end{array}$ & $\begin{array}{c}\text { Average size of } \\
\text { ejected fragments }(\mathrm{mm})\end{array}$ \\
\hline GZ-6 & 0.1 & - & - & - & 0 & - \\
\hline GZ-7 & 0.5 & $7.5 \times 10.0 \times 1.5$ & 78.19 & 3.50 & 0.48 & 43.17 \\
\hline GZ-8 & 1.0 & $13.3 \times 10.0 \times 1.3$ & 368.39 & 3.79 & 2.64 & 45.36 \\
\hline GZ-9 & 2.0 & $15.0 \times 10.0 \times 2.0$ & 394.75 & 5.19 & 5.31 & 64.46 \\
\hline
\end{tabular}
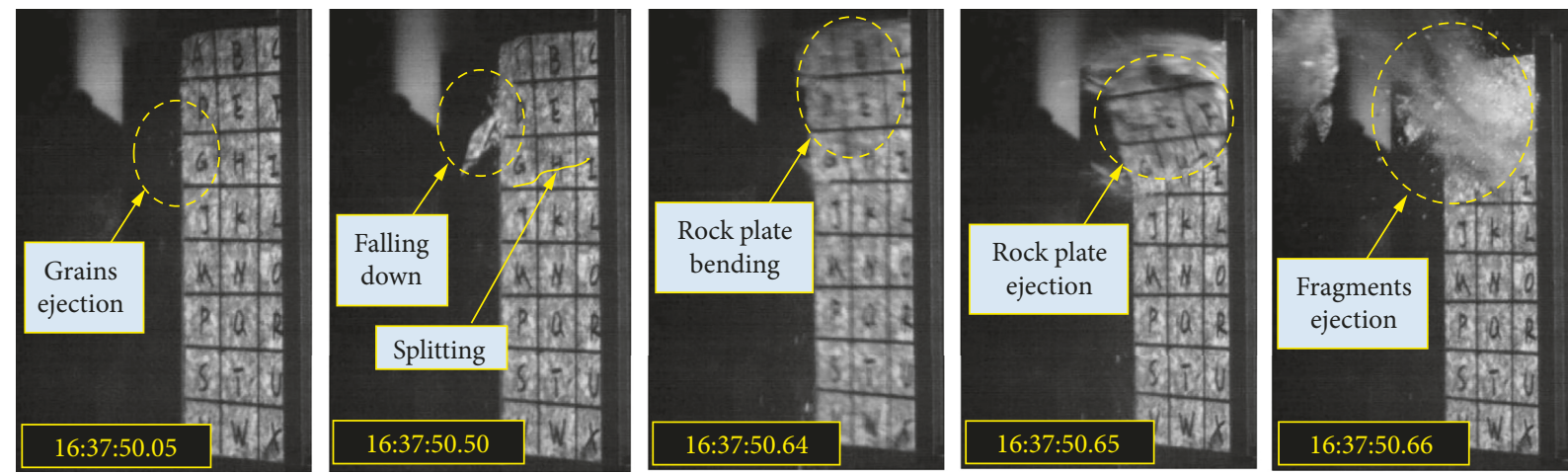

(a)
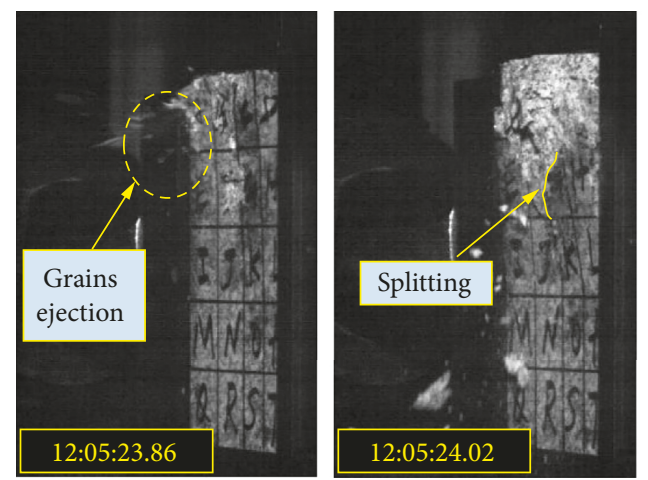
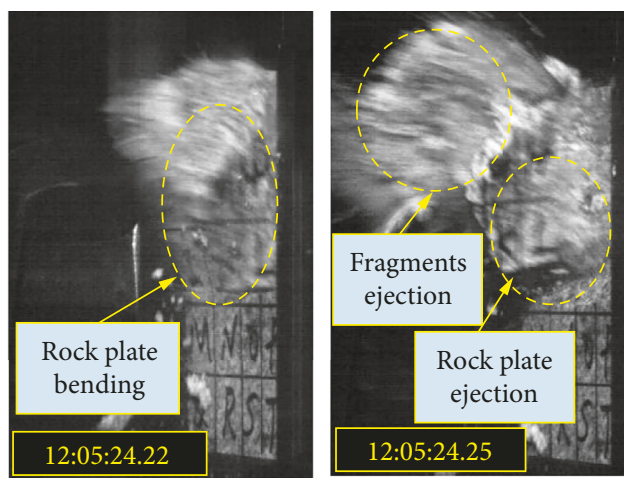

(b)

FIgure 19: Continued. 

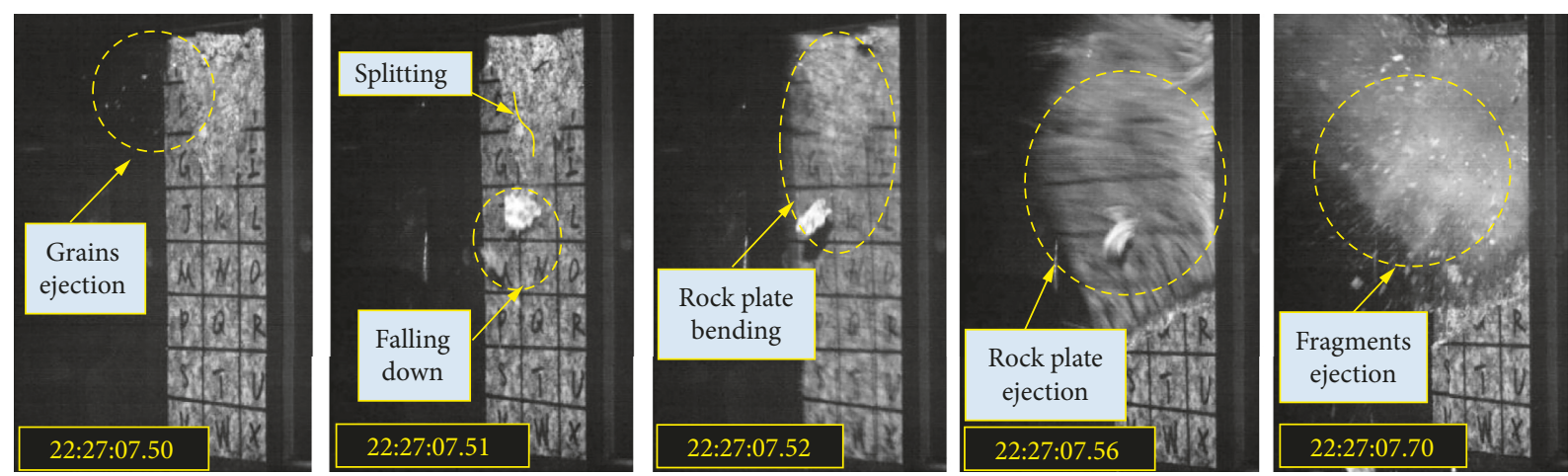

(c)

FIGURE 19: The rockburst process of the tested specimen under different support failure rates (the numbers at bottom-left corner of the pictures indicate the time in h:m:s.ms): (a) $v=0.5 \mathrm{MPa} / \mathrm{s}$; (b) $v=1.0 \mathrm{MPa} / \mathrm{s}$; (c) $v=2.0 \mathrm{MPa} / \mathrm{s}$.

notches of the specimens increased with the support failure rate.

(3) As presented in Table 6, the average size of the fragments of the tested specimen with a support failure rate of $2.0 \mathrm{MPa} / \mathrm{s}$ was $64.46 \mathrm{~mm}$, which was approximately $116.16 \%, 49.32 \%$, and $42.11 \%$ greater than those of the tested specimens with the support failure rates of $0.1,0.5$, and $1.0 \mathrm{MPa} / \mathrm{s}$. According to the size distributions and mass percentages of the fragments shown in Figure 21, the mass percentages of the coarse particles to all particles were always higher than $75 \%$. When compared with other tests, the mass percentages of the coarse particles of the tested specimen with a support failure rate of $2.0 \mathrm{MPa} / \mathrm{s}$ were the highest, up to $92.62 \%$.

(4) The kinetic energies of the ejected fragments are listed in Table 6. It can be observed that as the support failure rate increased, the qualities, average ejection rates, and kinetic energies of the ejected fragments increased. For the support failure rate with relatively small values such as $0.1 \mathrm{MPa} / \mathrm{s}$, there was enough time for microfractures to initiate and coalesce during the unloading process. The fully developed fractures dissipated large amounts of elastic strain energy in the prepeak phase, which prevented the occurrence of rockbursts.

(5) As shown in Figure 22, the vertical strains of the tested specimens were $13.24 \%, 13.11 \%, 12.88 \%$, and $12.50 \%$, which corresponded to support failure rates of $0.1,0.5$, 1.0 , and $2.0 \mathrm{MPa} / \mathrm{s}$, respectively. The vertical strains decreased as the support failure rate was incremented.

(6) Since the maximum major principal stresses of specimens GZ-6, GZ-7, GZ-8, and GZ-9 are $260 \mathrm{MPa}$. The accumulated elastic strain energies for the specimens GZ-6, GZ-7, GZ-8 and GZ-9 before unloading $\sigma_{3}$ are same. However, under the low unlading rate $(0.5 \mathrm{MPa} / \mathrm{s})$ condition, considerable fracture forms during the unloading process leading to much elastic strain energy are being dissipated. Consequently, quite a few energies change into kinetic energy of ejected fragments after unloading. With the increasing of loading, fewer fracture forms during the unloading process and fewer energies are dissipated, more energies change into kinetic energy of ejected energy, leading to a more violent rockburst.

\section{Discussion}

During underground construction, supports, which can effectively enhance the stability of the surrounding rock mass, have already been used to prevent rockbursts. However, support failure may trigger extremely intense rockbursts. In the present paper, the influence of support failures on rockbursts was experimentally investigated using a highly rigid true-triaxial rockburst machine, with the loading path of "loading on six surfaces and unloading on a single surface." Surface forces were directly applied to the rectangular specimens to simulate the intensive support strengthening the rock mass.

In addition, fragment ejection was the most significant characteristic of the dynamic rockbursts under varying static brittle failures. The kinetic energies of the ejected fragments can serve as the most reasonable indicator for evaluating the intensity of rockbursts and overcomes the defects of indirect indicators such as sound, number of ejected fragments, and rockburst notches. In this paper, a high-speed camera with dynamic image analysis software was used to estimate the rates of the ejected fragments, and then their kinetic energies were obtained. This approach provides a new method to assess rockburst intensity quantitatively.

Several findings from above experimental investigation can be drawn as follows.

First, support force plays an important role in the pregnant process of rockbursts in supported rocks. In general, increasing support force can prevent the occurrence of rockbursts to some extent. However, in many cases, extremely intense rockbursts often happen in the supported rocks $[1,4-6,26]$, indicating that more intensive rockbursts can be encountered in supported brittle hard rocks when 


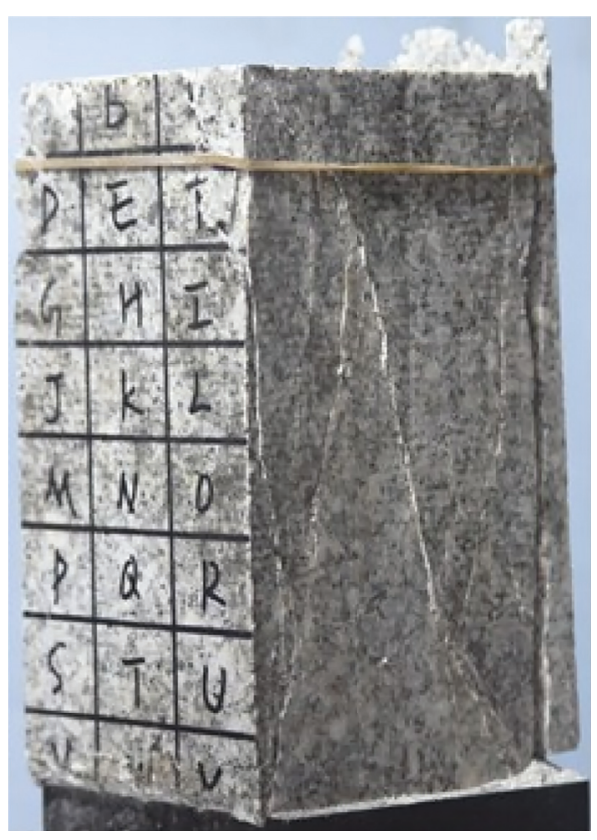

(a)

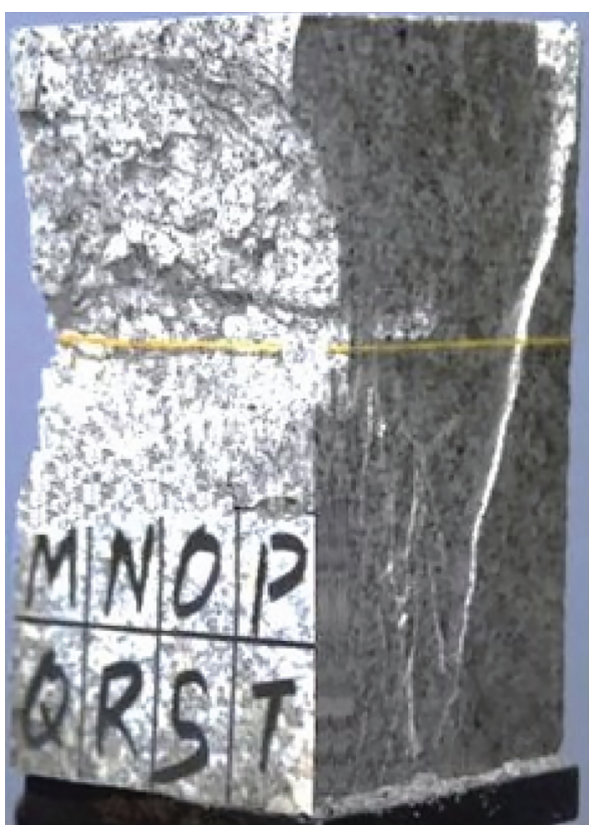

(c)

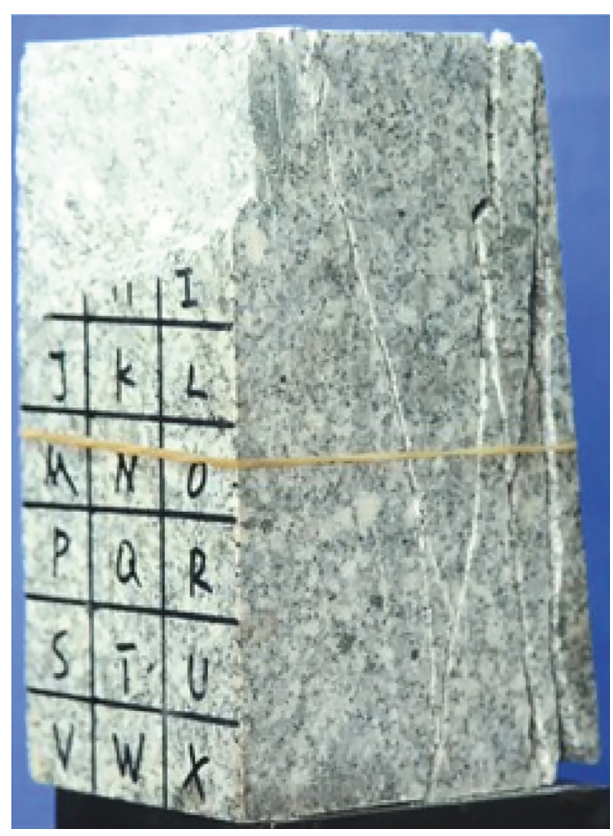

(b)

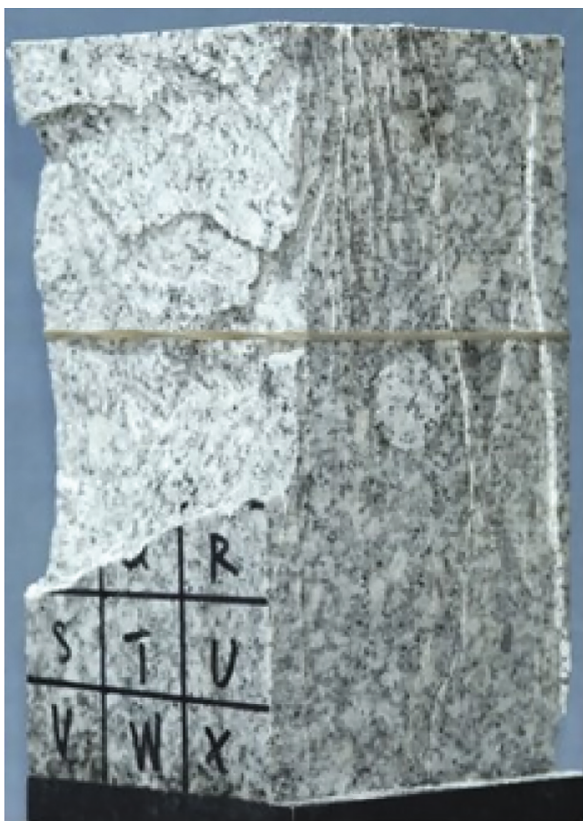

(d)

FIGURE 20: Failure form of the tested specimen under different support failure rates: (a) $v=0.1 \mathrm{MPa} / \mathrm{s} ;(\mathrm{b}) v=0.5 \mathrm{MPa} / \mathrm{s} ;$ (c) $v=1.0 \mathrm{MPa} / \mathrm{s}$; (d) $v=2.0 \mathrm{MPa} / \mathrm{s}$.

compared with rocks without support. This is because that the strength of rock mass is dependent on the confining stress. The support will provide a confining pressure for the rock, and the rock strength will therefore increase. Hence, increasing the support force means enhancing the integral strength of the rocks, and more elastic strain energy will be accumulated in the rocks; once the support fails, the carrying capacity of the rock will decrease rapidly, leading to the tangential stress exceeding the rock strength and further inducing rock failure. Then, considerable elastic energy will be released in an extremely short time, triggering more powerful and destructive rockbursts. Thus, different support strategies should be employed for different tunnels. For tunnels that are prone to weak or moderate intensity rockbursts, supports with adequate strength can increase the strength of rocks and lower the risk of rockburst occurrence. However, for the tunnels that are prone to extremely intense rockbursts, the engineering measurements such as loose blasting and pressure relief holes should be implemented before applying supports. 


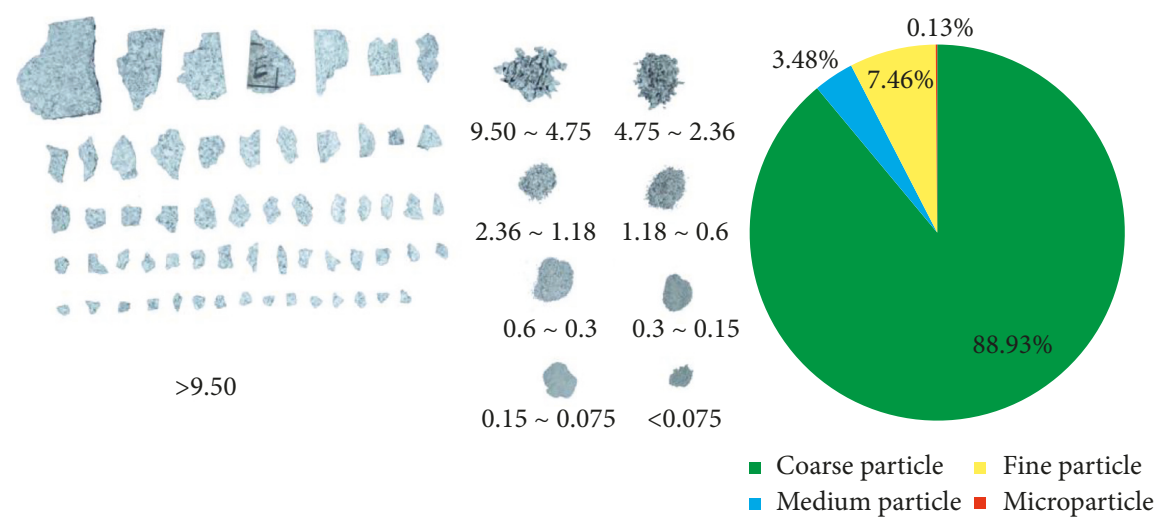

(a)
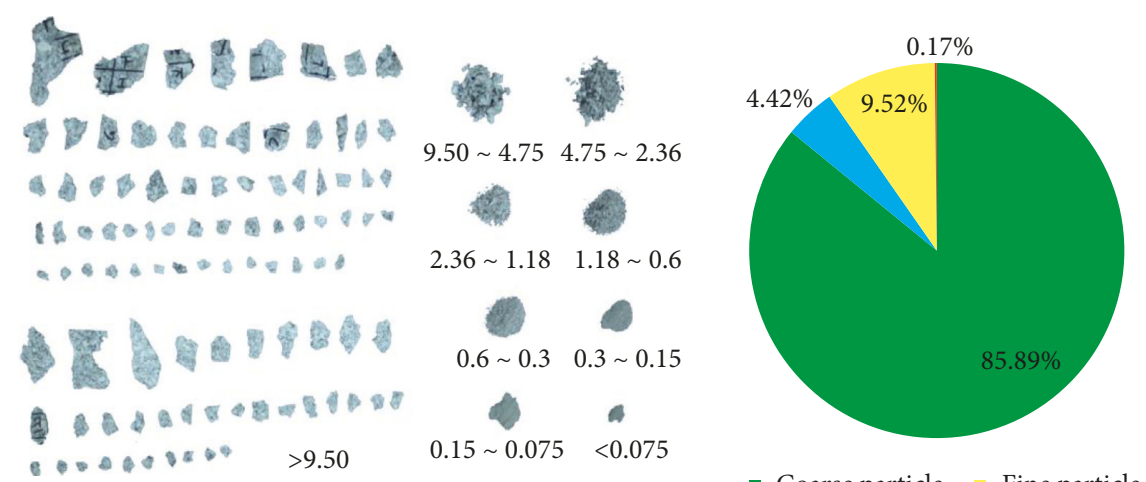

- Coarse particle Fine particle

- Medium particle | Microparticle

(b)

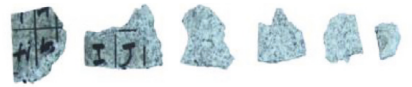

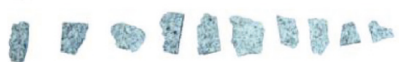
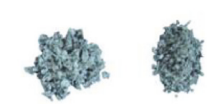

$9.50 \sim 4.75 \quad 4.75 \sim 2.36$

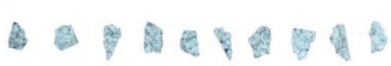

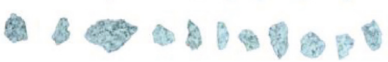

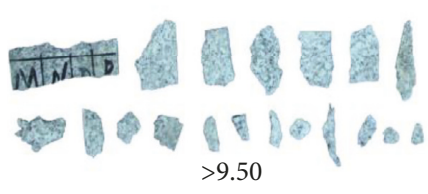

$2.36 \sim 1.18 \quad 1.18 \sim 0.6$
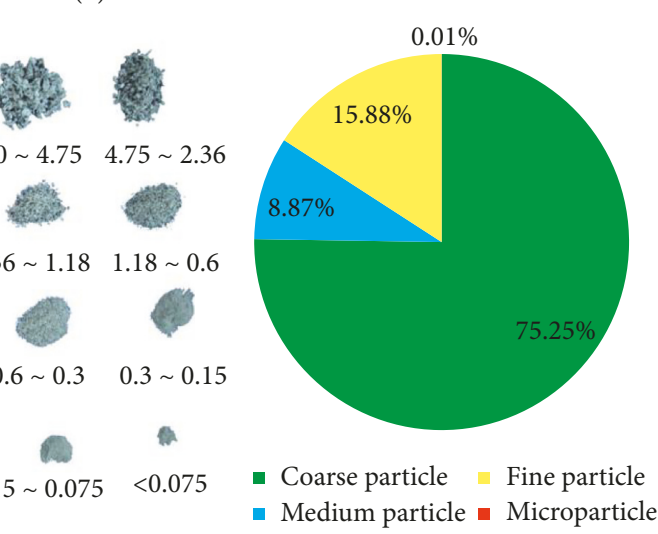

(c)
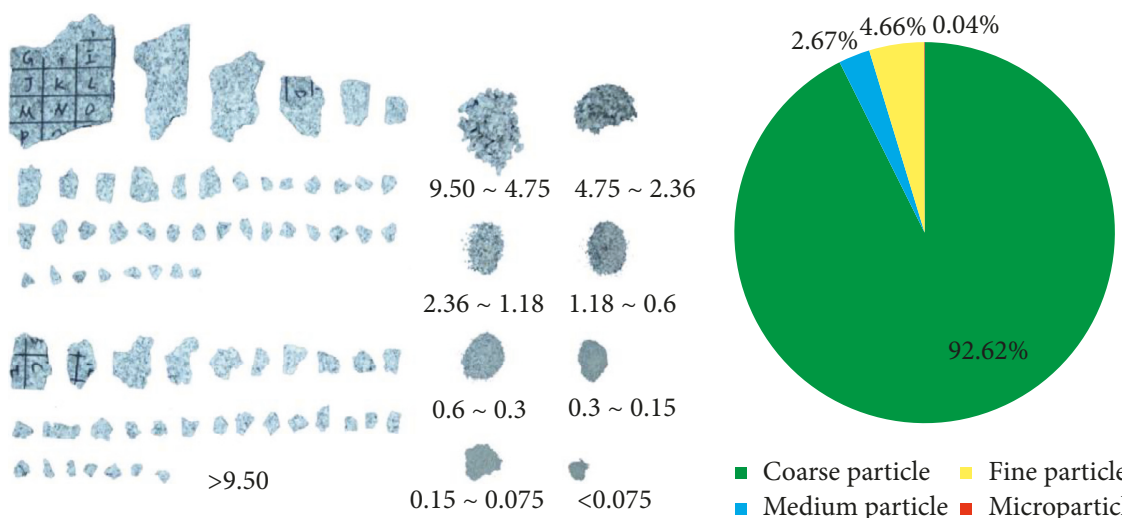

(d)

FIgURE 21: The size distribution of the fragments for different support failure rates (unit: $\mathrm{mm}$ ): (a) $v=0.1 \mathrm{MPa} / \mathrm{s}$; (b) $v=0.5 \mathrm{MPa} / \mathrm{s}$; (c) $v=1.0 \mathrm{MPa} / \mathrm{s} ;$ (d) $v=2.0 \mathrm{MPa} / \mathrm{s}$. 


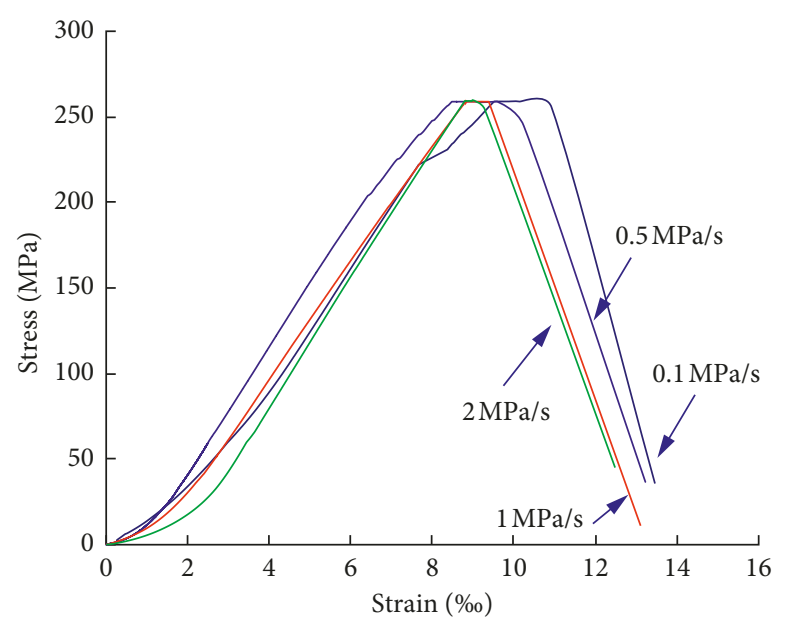

FIgURE 22: The axial stress-strain curve of the tested specimen under different support failure rates.

Second, we found that the timing of support failure obviously impacted the kinetic energy released during the rockbursts in the tests. With a given support force, the later the support fails, the more the elastic strain energy accumulates in the rock mass, the more the energy releases when the rock fails, and the more violent the corresponding rockburst process. Thus, for the tunnels that are prone to extremely intense rockbursts, it is unadvised to reinforce rocks blindly by increasing the carrying capacity of the support structure. Before the tangential stress increases to its maximum, the failure of a support with suitable carrying capacity can lead to the timely release of elastic strain energy, which is favorable to low occurrence or avoidance of extremely intense rockbursts.

Third, support failure rates also play an important role in rockbursts. Under the condition of a low failure rate, crack propagation and the large dissipation of elastic strain energy occur during the unloading state and reduce the amount of elastic energy converted into kinetic energy. Under a high failure rate condition, a low amount of energy is dissipated for crack initiation, propagation, and coalescence, and a large amount of elastic energy will be accumulated in the rocks before rock fails and released when rock fails. In this situation, considerable elastic strain energy changes into kinetic energy, inducing an intensive rockburst. As a matter of fact, the support failure is also a type of unloading of the rock mass, and support failure rate shows a similar influence on rockbursts as the unloading rate. There was good agreement with the experimental results regarding the influence of the unloading rate on the strainburst characteristics of granite under true-triaxial unloading conditions $[22,27]$; that is, the intensity of rockburst is dependent on the unloading rate. To date, the relation between the unloading rate and the kinetic energy of the ejected fragments from a rockburst has not been revealed. In this study, a definite conclusion that the kinetic energies of the ejection fragments of a rockburst tend to have a linear positive relationship with the support failure rate is indicated. Furthermore, the support failure rate is dependent on the energy absorption and deformation nature of the support structure.
In general, the failure rate of a flexible support is lower than that of a rigid support. Thus, it is necessary to develop flexible support structures that can absorb energy and large deformations to ensure the stability of the rocks for tunnels that are prone to rockbursts.

Finally, it should be noted that the influence of support failure on rockbursts from small rock specimens in a lab survey was presented in this paper, which is somewhat different from complex in situ conditions. Furthermore, the surface forces used in our test to simulate the support forces cannot describe the subtle interactions of flexible supports and rocks. Thus, it is essential to conduct the rockburst tests on bolted rock specimens to gain deeper insights into the mechanisms of the rockbursts for supported rocks.

\section{Conclusions}

(1) The experimental results indicate that the support force significantly influenced the rockbursts when support fails. As the support force increased, the prepeak accumulated elastic strain energy increased, the internal damage of the tested rock specimen in prepeak stage decreased, and the kinetic energies of the ejection fragments and the ratio of the kinetic energy and released strain energy increased.

(2) The timing of the support failure obviously affected the rockbursts. During the testing process, the later the minimum stress release, which indicates that the later the support failed, the greater the accumulated elastic strain energy was and the larger the kinetic energies of the ejected fragments and the ratio of the kinetic energies and released strain energies were.

(3) The kinetic energies of the ejected fragments of the rockbursts exhibited a linearly increasing trend with an increment in the support failure rate. With the increment in the failure rate, the final failure changed from static failure to a dynamic rockburst, the prepeak damage of the rock specimens decreased, and the accumulated absolute energy of the acoustic 
emissions decreased, but the intensities of the rockbursts increased. Hence, flexible supports, which can absorb the energy, should be used to reinforce the surrounding rock in underground excavations. It can share the same strain as the surrounding rock and dissipate part of the elastic strain energy of the surrounding rock. In this case, the failure rate of the support will decrease, resulting in lower intensities of elastic energy releases during rockburst processes.

(4) A significant finding from the present study is that enhancing the strength or force of supports for preventing rockbursts is maybe not reasonable for tunnels under high ground stresses where the rock masses are prone to rockbursts. It not only increases the costs of supports but also significantly raises the risk of intensive rockbursts. Furthermore, flexible supports rather than rigid supports should be a good choice for reinforcing surrounding rocks that are prone to rockbursts in deep underground excavations.

\section{Data Availability}

The data used to support the findings of this study are included within the article.

\section{Conflicts of Interest}

The authors declare that they have no conflicts of interest.

\section{Acknowledgments}

The authors would like to thank the National Natural Science Foundation of China under Grant no. 41472329. The work in this paper was also supported by the Opening Fund of State Key Laboratory of Geo-Hazard Prevention and Geo-Environment Protection (Chengdu University of Technology) under Grant no. SKLGP2017K022 and Guangxi Natural Science Foundation under Grant no. 2016 GXNSFGA380008.

\section{References}

[1] M. Cai, "Influence of intermediate principal stress on rock fracturing and strength near excavation boundaries-insight from numerical modeling," International Journal of Rock Mechanics and Mining Sciences, vol. 45, no. 5, pp. 763-772, 2008.

[2] S. J. Li, X. T. Feng, Z. H. Li, B. R. Chen, C. Q. Zhang, and H. Zhou, "In situ monitoring of rockburst nucleation and evolution in the deeply buried tunnels of Jinping II hydropower station," Engineering Geology, vol. 137-138, pp. 85-96, 2012.

[3] M. Cai, "Principles of rock support in burst-prone ground," Tunnelling and Underground Space Technology, vol. 36, pp. 46-56, 2013.

[4] X. T. Feng, B. R. Chen, C. Q. Zhang, S. J. Li, and S. Y. Wu, Mechanism, Warning and Dynamic Control of Rockburst Development Processes, Science Press, Beijing, China, 2013, in Chinese.
[5] H. J. Wang, D. A. Liu, W. L. Gong, and L. Y. Li, "Dynamic analysis of granite rockburst based on the PIV technique," International Journal of Mining Science and Technology, vol. 25, no. 2, pp. 275-283, 2015.

[6] C. Q. Zhang, X. T. Feng, H. Zhou, S. L. Qiu, and W. P. Wu, "Case histories of four extremely intense rockbursts in deep tunnels," Rock Mechanics and Rock Engineering, vol. 45, no. 3, pp. 275-288, 2012.

[7] B. H. G. Brady and E. T. Brown, Rock Mechanics: For Underground Mining, Springer Science \& Business Media, Berlin, Germany, 2013.

[8] E. Broch and S. Sørheim, "Experiences from the planning, construction and supporting of a road tunnel subjected to heavy rockbursting," Rock Mechanics and Rock Engineering, vol. 17, no. 1, pp. 15-35, 1984.

[9] W. D. Ortlepp, "The behaviour of tunnels at great depth under large static and dynamic pressures," Tunnelling and Underground Space Technology, vol. 16, no. 1, pp. 41-48, 2001.

[10] B. Simser, W. C. Joughin, and W. D. Ortlepp, "The performance of Brunswick mines rockburst support system during a severe seismic episode," Journal of the Southern African Institute of Mining and Metallurgy, vol. 102, pp. 217-223, 2002.

[11] P. K. Kaiser, Canadian Rockburst Support Handbook: Prep. for Sponsors of the Canadian Rockburst Research, Geomechanics Research Centre, Crawley, Australia, 1996.

[12] M. C. He, W. L. Gong, J. Wang et al., "Development of a novel energy-absorbing bolt with extraordinarily large elongation and constant resistance," International Journal of Rock Mechanics and Mining Sciences, vol. 67, pp. 29-42, 2014a.

[13] P. K. Kaiser and M. Cai, "Design of rock support system under rockburst condition," Journal of Rock Mechanics and Geotechnical Engineering, vol. 4, no. 3, pp. 215-227, 2012.

[14] N. G. W. Cook, "The basic mechanics of rockbursts," Journal of the Southern African Institute of Mining and Metallurgy, vol. 63, pp. 71-81, 1963.

[15] J. A. Wang and H. D. Park, "Comprehensive prediction of rockburst based on analysis of strain energy in rocks," Tunnelling and Underground Space Technology, vol. 16, no. 1, pp. 49-57, 2001.

[16] Q. Jiang, G. S. Su, X. T. Feng, J. Cui, P. Z. Pan, and J. Q. Jiang, "Observation of rock fragment ejection in post-failure response," International Journal of Rock Mechanics and Mining Sciences, vol. 74, pp. 30-37, 2015.

[17] K. H. Höfer and K. Thoma, "Triaxial tests on salt rocks," International Journal of Rock Mechanics and Mining Sciences \& Geomechanics Abstracts, vol. 5, no. 2, pp. 195-196, 1968.

[18] M. D. G. Salamon, "Stability, instability and design of pillar workings," International Journal of Rock Mechanics and Mining Sciences \& Geomechanics Abstracts, vol. 7, no. 6, pp. 613-631, 1970.

[19] A. Z. Hua and M. Q. You, "Rock failure due to energy release during unloading and application to underground rock burst control," Tunnelling and Underground Space Technology, vol. 16, no. 3, pp. 241-246, 2001.

[20] M. C. He, J. L. Miao, D. J. Li, and C. G. Wang, "Experimental study on rockburst processes of granite specimen at great depth," Chinese Journal of Rock Mechanics and Engineering, vol. 26, pp. 865-876, 2007, in Chinese.

[21] X. G. Zhao and M. Cai, "Influence of specimen height-towidth ratio on the strainburst characteristics of Tianhu granite under true-triaxial unloading conditions," Canadian Geotechnical Journal, vol. 52, no. 7, pp. 890-902, 2014. 
[22] X. G. Zhao, J. Wang, M. Cai et al., "Influence of unloading rate on the strainburst characteristics of Beishan Granite under true-triaxial unloading conditions," Rock Mechanics and Rock Engineering, vol. 47, no. 2, pp. 467-483, 2014.

[23] W. L. Gong, Y. Y. Peng, H. Wang, M. C. He, L. R. E Sousa, and J. Wang, "Fracture angle analysis of rock burst faulting planes based on true-triaxial experiment," Rock Mechanics and Rock Engineering, vol. 48, no. 3, pp. 1017-1039, 2015.

[24] G. S. Su, Z. Y. Chen, J. W. Ju, and J. Q. Jiang, "Influence of temperature on the strainburst characteristics of granite under true triaxial loading conditions," Engineering Geology, vol. 222, pp. 38-52, 2017a.

[25] G. S. Su, J. Q. Jiang, S. B. Zhai, and G. L. Zhang, "Influence of tunnel axis stress on strainburst: an experimental study," Rock Mechanics and Rock Engineering, vol. 50, no. 6, pp. 1551-1567, 2017b.

[26] M. Cai and D. Champaigne, "Influence of bolt-grout bonding on MCB conebolt performance," International Journal of Rock Mechanics and Mining Sciences, vol. 49, pp. 165-175, 2012.

[27] M. C. He, F. Zhao, S. Du, and M. J. Zheng, "Rockburst characteristics based on experimental tests under different unloading rates," Rock and Soil Mechanics, vol. 35, pp. 2737-2747, 2014b, in Chinese. 


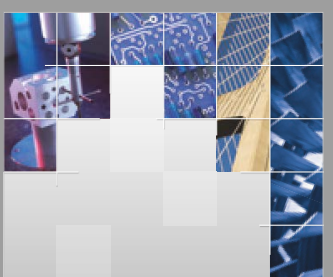

\section{Enfincering}
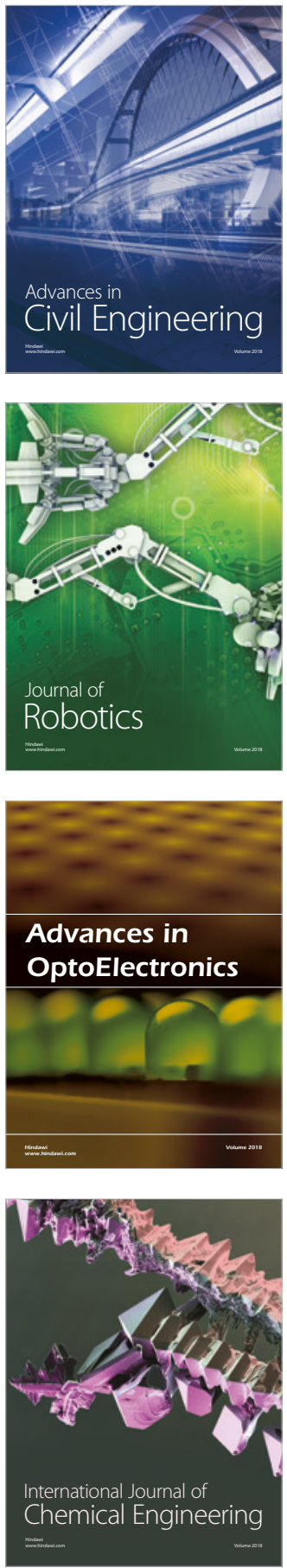

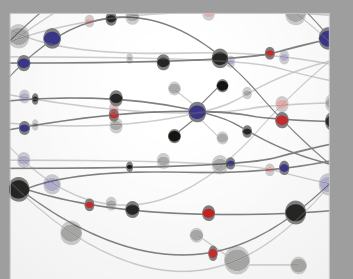

\section{Rotating \\ Machinery}

The Scientific World Journal

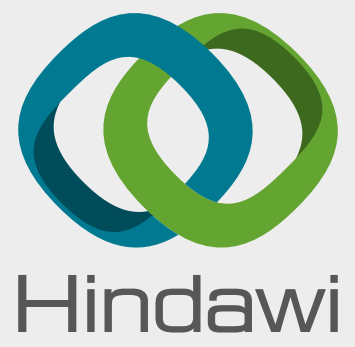

Submit your manuscripts at

www.hindawi.com
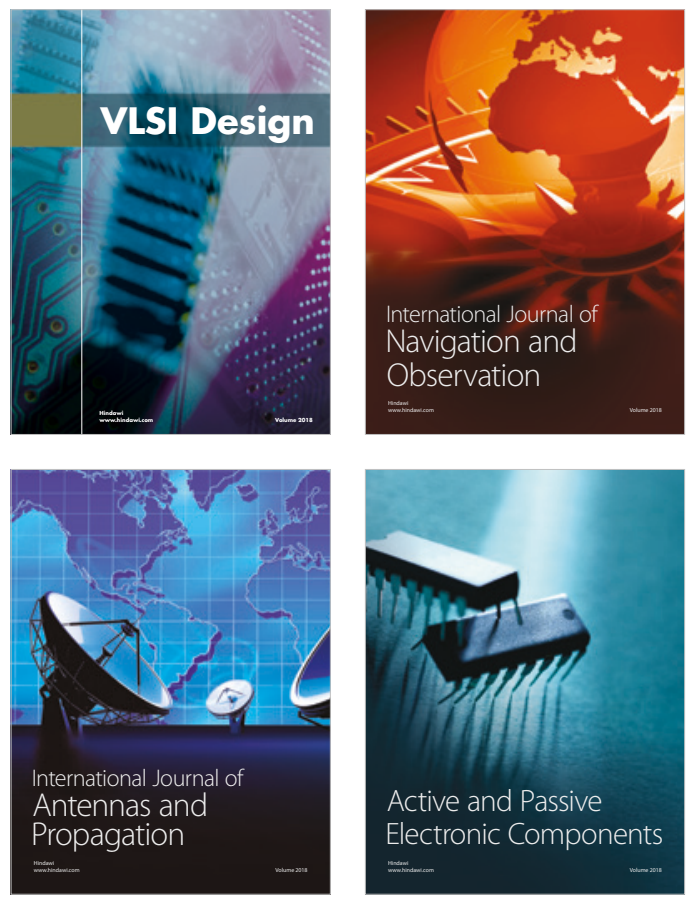
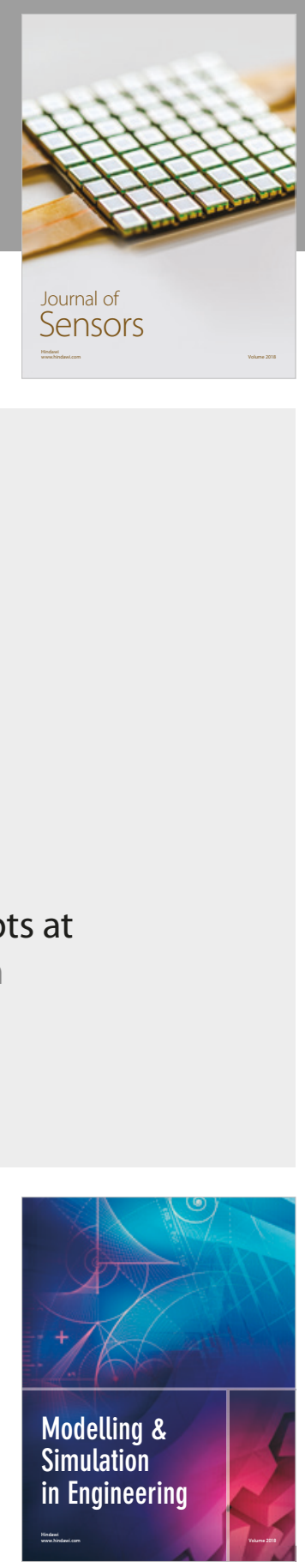

\section{Advances \\ Multimedia}
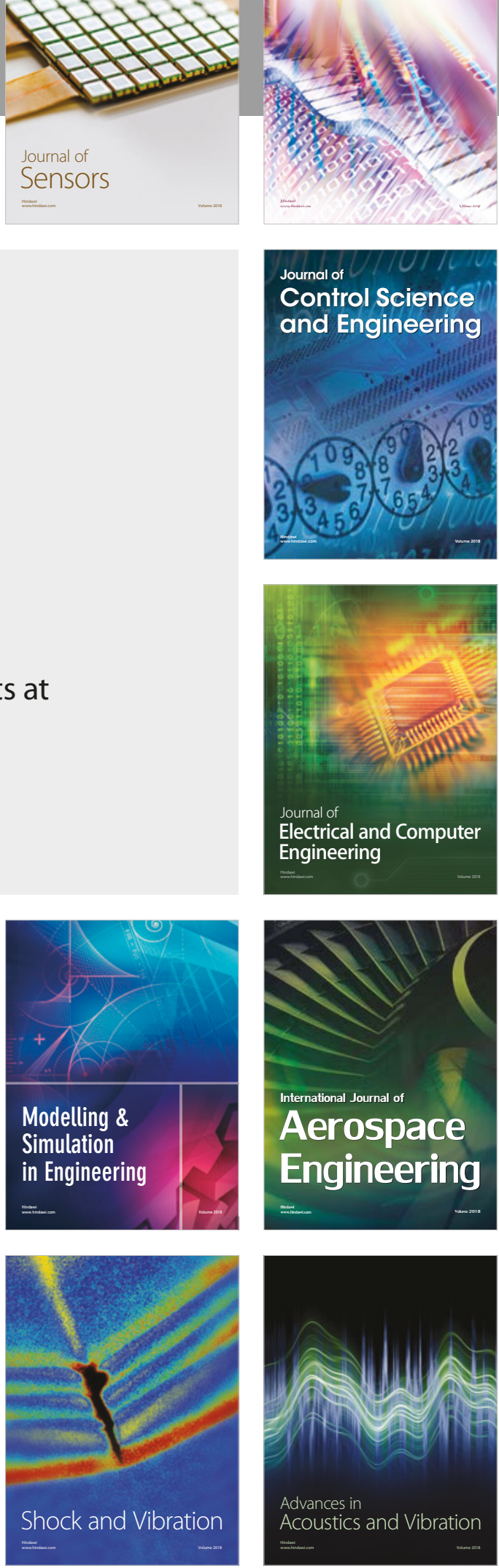